\title{
Animal Models of Mycobacteria Infection
}

\author{
Diane J. Ordway and lan M. Orme \\ Mycobacteria Research Laboratories, Department of Microbiology, Immunology and Pathology, \\ Colorado State University, USA
}

\begin{abstract}
This unit describes the infection of mice and guinea pigs with mycobacteria via various routes, as well as necropsy methods for the determination of mycobacterial loads within target organs. Additionally, methods for cultivating mycobacteria and preparing stocks are described. The protocols outlined are primarily used for M. tuberculosis, but can also be used for the study of other non-tuberculosis mycobacterial species.
\end{abstract}

A wide variety of animal models have been used to test new vaccines and drugs (Orme, 2005; Orme, 2006; McMurray, 2005; Johnson, 2005; Williams 2009). Mice are the most widely used small animal model because of the broad availability of immunological reagents, relatively low cost and the availability of inbred and genetically engineered strains with well defined genotypes. The one notable disadvantage of the mouse model is that the pulmonary and extra-pulmonary pathology following aerosol challenge lacks important morphologic features that are commonly seen in humans with untreated tuberculosis. To model these aspects the guinea pig low-dose aerosol infection model has been further developed in recent years since it shares many of these clinical features with the human disease (McMurray, 2003; Basaraba, 2008).

Both mice and guinea pigs can be productively infected with strains of Mycobacterium tuberculosis. However, because of the differences in susceptibility between the two models, the mouse is generally used to define the host protective immune response to the disease, while the guinea pig is used as a model of the progressive pathology of tuberculosis.

Mice can be infected with mycobacteria by a variety of routes, including intravenous or aerogenic routes. Intravenous inoculation of mice with $1.0 \times 10^{5}-10^{6}$ colony-forming units (cfu) of M.tuberculosis results in a systemic infection in which a protective immune response becomes evident over the first 1 to 2 weeks. After this response, the infection

\section{Key References}

Bloom, 1994. See above.

This book is a comprehensive treatise on tuberculosis and contains valuable information for the researcher.

Leong, F. J., Dartois. V., Dick, T. 2010. A Color Atlas of Comparative Pathology of Pulmonary Tuberculosis. CRC Press, Bocan Raton,

This book will be of interest to readers interested in the pathology of tuberculosis in the guinea pig model.

Internet Resources

http://www.cdc.gov/tb/

www.iata.org

http://www.cdc.gov/niosh/topics/tb/

http://www.cdc.gov/biosafety/publications/bmbl5/index.htm

http://www.cdc.gov/niosh/pt84abs2.html

http://www.osha.gov/SLTC/bloodbornepathogens/index.html

Contributed by Diane J. Ordway Ian M. Orme, Mycobacteria Research Laboratories, Colorado State University, Fort Collins,

Colorado 
enters a chronic phase, particularly in the spleen and lungs, in which bacterial numbers do not appreciably change over long periods of time.

The aerogenic infection route for mice and guinea pigs is the most relevant to the human disease. Lung infections can be simulated by intra-nasal or intra-tracheal inoculation techniques, but in these protocols there tends to be a high degree of variability in the ultimate delivery of bacilli into the alveoli. The most reproducible technique available is the generation of an aerosol cloud of very small droplet nuclei containing the bacilli. These nuclei are inhaled by the animal and deposited deep into the alveolar regions of the lungs.

This unit describes the infection of mice and guinea pigs with mycobacteria via the aerogenic route (see Basic Protocol 1 and Basic Protocol 2), infection of mice via the intravenous route (see Alternate Protocol), necropsy methods for the determination of mycobacterial loads within target organs (see Basic Protocol 3), assessment of organ pathology (see Basic Protocol 4), and methods that can be used to measure the host immune response (see Basic Protocol 5). Biosafety considerations for working with M. tuberculosis and specific guidelines for using the inhalation exposure system are also addressed (see Strategic Planning). Finally, methods for cultivating mycobacteria and preparing stocks are described (see Support Protocol). The protocols outlined are primarily used for $M$. tuberculosis, but can also be used for the study of other opportunistic mycobacterial species such as M. avium. The unit therefore primarily discusses and focuses on model systems involving $M$. tuberculosis infection, but can be readily adapted for use with other species.

\section{STRATEGIC PLANNING}

\section{Biosafety Considerations in Performing Experiments with Mycobacteria}

The use of mycobacteria, and specifically Mycobacterium tuberculosis, in the research laboratory setting and in animal modeling systems poses very serious biosafety concerns that must be addressed. Biosafety protocols and facilities need to be in place prior to any experimental work with this etiologic agent. Most clinical laboratories have the ability to handle very small inocula of $M$. tuberculosis within an appropriate Class II biosafety cabinet located in a restricted-access laboratory. In research laboratory settings involved in animal modeling systems, however, all operations should be done in appropriate biosafety level 3 (BSL-3) and animal biosafety level 3 (ABL-3) laboratory facilities. The National Institutes of Health (NIH), Centers for Disease Control (CDC), and Occupational Safety and Health Administration (OSHA) have specific guidelines and regulations for laboratories handling BL-3 human pathogens, and each laboratory planning to conduct experiments with $M$. tuberculosis should adopt these guidelines and regulations into their standard laboratory protocols. Moreover, any work with $M$. tuberculosis should have prior approval of the Institutional Biosafety Committee and/or Biosafety Officer prior to starting any research project with M. tuberculosis. The laboratory should have an Exposure Control Plan in place before starting operation, and all personnel should be familiar with all protocols for handling M. tuberculosis. OSHA regulations governing the handling of BL-3 human pathogens (OSHA, 1991) as well as CDC/NIH Guidelines for Biosafety (CDC, 1994, 1998; CDC/NIH, 1993) should be followed.

Biosafety laboratories should either be stand-alone facilities or be part of a larger animal facility. If there are regular open laboratories on floors above the ABL-3/BL-3 facilities, the air-handling systems should be very carefully checked on a regular basis. However, this type of architectural arrangement is not recommended. If the facility includes any form of aerosol generation device, this should be kept separately in a room under the lowest air pressure relative to the rest of the ABL-3/BL-3 facility. In the authors' research laboratory, BL-3 facilities have a negative-pressure graduated air flow handling system in place, and all 
exhaust air from the facilities is high-efficiency particulate air (HEPA)-filtered. The incorporation of secondary back-up HEPA filters and a negative-pressure air system is recommended, but not essential. The ABL-3 facility should also incorporate a shower-in/ shower-out policy for all personnel, which helps prevents not only carriage of bacteria but also helps prevent the potential transmission of murine or other animal viruses from other areas of the animal facility.

All personnel should wear appropriate protective over-clothing or surgical scrubs, as well as gloves, hair covers, facility-specific shoes or boots, and respirators. An air purifying disposable mask-type respirator approved by the National Institute of Occupational Safety and Health (NIOSH) is required at all times. The respirator should have $\geq 95 \%$ efficiency at filtering dusts and mists $>0.3 \mu \mathrm{m}$ in size and be of the HEPA, N, P, or R series (refer to CDC/NIOSH, 1995; OSHA, 1991). The authors recommend the use of powered positivepressure air-purifying respirator helmets (RACAL AC3 and Breath Easy models, RACAL Health and Safety). These helmets consist of a backpack blower motor fitted with HEPA filters, which delivers sterile air through a tube into the crown of the helmet. HEPA-filtered air flows into the face shield of the helmet and produces a positive-pressure environment for the wearer. A disposable mask-type respirator should always be worn in conjunction with the respirator helmet. Infection procedures, tissue homogenization, and plating can all potentially create significant aerosols, which are the primary source of danger aside from needle sticks.

ABL-3 laboratories involved in experiments with M. tuberculosis should be equipped with a Class II biosafety cabinet as well as a glove box system with an air interlock and HEPAfiltered air intake and exhaust. All personnel should be part of a tuberculosis surveillance program and have a purified protein derivative (PPD) skin test performed semiannually. Individuals vaccinated with the M. bovis strain BCG (Bacillus of Calmette and Guérin), as well as PPD-positive individuals, should consider having a chest $\mathrm{X}$ ray every 1 to 2 years.

\section{Guidelines for Use of the Glas-Col Middlebrook Inhalation Exposure System}

The aerosol-generating instrument developed by Middlebrook (1952) is currently the most widely used in the field, and hence is described in detail here. This instrument can be utilized for mice and guinea pigs, but it is recommended for mice as the Madison (Generation III) Inhalation Exposure System is larger and holds more guinea pigs. This instrument is currently manufactured by Glas-Col, and consists of a large circular aerosol chamber containing a circular basket/cage with five pie-shaped compartments into which the animals are placed. Each of the compartments can accommodate as many as twenty five mice, two 500-gram guinea pigs, or one small rabbit. The aerosol chamber has a heavy acrylic lid with two locking handles that lock tightly against a heavy-duty rubber gasket. The lid also has two ultraviolet lamps on its underside that are used during the decontamination cycle of instrument operation. The front of the instrument consists of a digital computer control keypad for the programming of various cycles of operation, two air flow rotometers, two air control knobs, and on/off switches for the instrument power, UV lamps, and program/keypad.

On the front of the instrument are three stainless steel socket joints with clamps for attachment of the glass venturi-nebulizer unit. This is filled with a suspension of bacilli at a predetermined concentration for delivery into the aerosol chamber (see Basic Protocol 1). When the instrument is in operation, compressed air flows through the nebulizer and produces a very fine mist of the bacterial suspension, which is then carried by a larger volume of air into the aerosol chamber. The air flow then exits the chamber through two HEPA filters and a super-heated exhaust stack where the air is subsequently incinerated before release. The keypad controls the duration of the various cycles involved in the 
aerosol-generating process. The first cycle is the preheat cycle, in which the incinerator is allowed to attain a suitable temperature prior to initiation of the nebulization cycle. The nebulization cycle does not engage until the preheat cycle is completed. During the nebulization cycle the compressed air is routed through the venturi section of the nebulizer to create droplet nuclei containing the bacilli, which are then carried into the main air flow and into the chamber containing the animals. The third cycle is cloud decay, during which the aerosol chamber is purged with fresh air and the bacterial mist is dissipated. The ultraviolet cycle is the final cycle, in which UV lamps are switched on to decontaminate the top surfaces of the basket.

\section{BASIC PROTOCOL 1 \\ AEROSOL INFECTION OF MICE WITH MYCOBACTERIA}

Because the natural route of tuberculosis infection in humans is the lung, the most precise animal models try to mimic this route. Intranasal or intratracheal inoculation of mice can give rise to pulmonary infection, but the most reproducible technique is to generate an aerosol that is inhaled by the animal.

Animals are exposed to M. tuberculosis using bacterial stocks with established cfu titers and specific lot numbers (see Support Protocol). Familiarity with the use of the inhalation exposure system (IES) used to infect mice is important to the success of this procedure (see Strategic Planning). The procedure described below provides detailed instructions for using the inhalation system to infect mice with Mycobacterium.

CAUTION: All airborne infections of animals using Mycobacterium tuberculosis must be performed in an appropriate ABL-3 laboratory (see Strategic Planning).

NOTE: The parameters given here are intended only to serve as a guide, and the individual researcher should test the operation of the IES empirically by doing a series of experimental aerosol challenges at different concentrations of bacilli in order to establish the individual differences that may exist between instruments.

\section{Materials}

Class II Biosafety cabinet

Mice or guinea pigs to be infected

$1.5-\mathrm{ml}$ frozen stock suspensions of M. tuberculosis $\left(5.0 \times 10^{7}\right.$ to $5.0 \times 10^{8} \mathrm{cfu} / \mathrm{ml}$; see Support Protocol)

$5 \%(\mathrm{v} / \mathrm{v})$ lysol (VWR)

$70 \%(\mathrm{v} / \mathrm{v})$ ethanol

Sterile $\mathrm{H}_{2} \mathrm{O}$

$7 \mathrm{H} 10$ or $7 \mathrm{H} 11$ agar quadrant petri plates (Fisher)

Laboratory glassware detergent (VWR)

Pan sonicator (Branson)

Absorbent hood blotters with plastic backing (VWR)

Paper towels

Disposable surgical gown (VWR)

Stainless steel pipet boat with cover (VWR) 
1-cc disposable tuberculin syringes fitted with $26 \frac{1}{2}-\mathrm{G}$ needles (VWR)

Sharps container (VWR)

50-ml conical polypropylene centrifuge tube (Fisher)

$12 \times 125-\mathrm{mm}$ culture tubes with caps

1.0-ml disposable serological pipets (Falcon)

Resealable polypropylene bags

Middlebrook inhalation exposure system (IES; Glas-Col model 099C A4212; see Strategic Planning)

RACAL AC3 or PAPR or Breathe Easy respirator unit (Lab Safety Supply)

Glass nebulizer-venturi (Glas-Col), sterilized and wrapped

10-cc disposable syringes fitted with $18-\mathrm{G}$ needles (VWR)

Stainless steel pan and cover, of sufficient size to accommodate nebulizer-venturi (VWR)

Infection baskets (Glas-Col), sterilized

\section{Prepare mycobacterial aerosol suspension}

1. Remove a vial containing the mycobacterial species of interest, and gently thaw at room temperature by placing in water in a pan sonicator. Thaw completely.

2. Turn on the sonicator for 10 to $15 \mathrm{sec}$ to disperse any clumps of mycobacteria that may have formed during freezing. Vortex momentarily to further disrupt any clumps of bacilli.

3. Disinfect the work surfaces of a Class II biosafety cabinet using 5\% Lysol followed by $70 \%$ ethanol. Place all cleaning materials into an autoclave bag for proper disposal. Place absorbent hood blotters with plastic backing on the work surface of the cabinet and soak with 5\% Lysol.

This is done to minimize/neutralize any spills or splatters that occur during manipulations with mycobacteria.

4. Fill a stainless steel pipet boat with 5\% Lysol to a 1.0- to 2.0-cm depth and place toward the rear of the work surface. Place a sharps container to the side to accommodate syringes and needles.

5. Place the vial in the cabinet, disinfect the top of the butyl rubber septum with $70 \%$ ethanol.

6. Carefully remove the mycobacterial suspension from the vial with a 1-cc tuberculin syringe fitted with a $261 / 2-G$ needle and expel back into the vial. Repeat back and forth into the vial ten to twenty times without removing the needle to mix the suspension and break up any small clumps of bacilli.

NOTE: Tuberculin syringes that have a pre-attached needle are highly recommended.

7. Remove the desired volume of mycobacterial suspension with the syringe and carefully inject down the side of a 50-ml conical polypropylene centrifuge tube containing sterile water so that the final volume is $5 \mathrm{ml}$ and the final dilution results in the desired working titer $(\mathrm{cfu} / \mathrm{ml})$ for use in the IES. Place the syringe in the sharps container for disposal. 
The volume of mycobacterial suspension depends on the numbers of animals to be exposed. The exposure chamber basket can accommodate $\sim 125$ mice or 10 small (500-gram) guinea pigs. The basket has five equal compartments for separation of experimental groups of animals (25 mice or 2 guinea pigs per compartment). The number of animals (animals per group and number of time points following aerogenic challenge) depends on experimental design.

In most experiments involving the infection of mice with $\mathrm{M}$. tuberculosis, the standard challenge dose is 50 to $100 \mathrm{cfu}$ deposited in the lungs. Guinea pigs, due to their inherent susceptibility to tuberculosis, routinely receive a challenge dose of 10 to $50 \mathrm{cfu}$ (sometimes even lower). To result in an uptake of $100 \mathrm{cfu}$ in mice, the mycobacterial suspension should be at $2.0 \times 10^{6} \mathrm{cfu} / \mathrm{ml}$ in a total volume of $5.0 \mathrm{ml}$ sterile water $\left(1.0 \times 10^{7} \mathrm{cfu}\right.$ total, or five logs higher than the anticipated cfu delivery). About $80 \%$ to $100 \%$ (4 to $5 \mathrm{ml}$ ) of this suspension should be nebulized over the 40-min cycle.

The preparation of mycobacterial suspensions for guinea pigs also follows the five-log algorithm, but the duration of the aerosol exposure is shortened $5 \mathrm{~min}$ and only 0.5 to $1.0 \mathrm{ml}$ of suspension is delivered through the nebulizer at completion of the aerosol exposure. As guinea pigs are more susceptible and have a larger lung volume than mice, they inhale a larger volume of air per unit time, and thus require a shorter exposure time.

\section{Confirm titer of starting suspension}

8. Assemble five sterile $12 \times 125-\mathrm{mm}$ culture tubes each containing $4.5 \mathrm{ml}$ sterile saline. Label three $7 \mathrm{H} 10$ or $7 \mathrm{H} 11$ agar quadrant petri plates to give duplicate quadrants of six dilutions as follows: $10^{0}, 10^{-1}, 10^{-2}, 10^{-3}, 10^{-4}$, and $10^{-5}$. Label the tubes as $10^{-1}$ to $10^{-5}$.

Although steps 8 to 13 can be omitted, they are strongly recommended as a means of confirming the challenge dose loaded into the nebulizer.

9. Using a 1.0-ml sterile serological pipet, remove $0.7 \mathrm{ml}$ working mycobacterial suspension (from step 1), add $0.5 \mathrm{ml}$ to the first culture tube $\left(10^{-1}\right.$ dilution), and plate the remaining $0.2 \mathrm{ml}$ onto the duplicate quadrants labeled $10^{0}$. Discard the pipet into the stainless steel pipet boat containing 5\% Lysol.

Pipetting operations during the serial dilution process should be done with extreme care in order to prevent aerosol generation. Any small spills or drops during the pipetting process should be immediately disinfected with 5\% Lysol.

10. Gently swirl the contents of the $10^{-1}$ dilution tube. Use a new $1.0-\mathrm{ml}$ serological pipet to remove $0.7 \mathrm{ml}$, transfer $0.5 \mathrm{ml}$ to the next culture tube $\left(10^{-2}\right)$, and plate the remaining $0.2 \mathrm{ml}$ onto the duplicate quadrants labeled $10^{-1}$.

11. Repeat this process until the final $10^{-5}$ dilution has been plated.

12. Place plates upright in a resealable polypropylene bag and incubate in the dark at $37^{\circ} \mathrm{C}$ for $\sim 3$ weeks.

After incubation mycobacterial colonies should become visible and countable (see step 37). 
13. Disinfect the biological containment cabinet after use. Double bag culture tubes, stock vials, and the pipet boat in autoclave bags and tape with heat-sensitive autoclave tape.

\section{Infect animals by exposure to aerosol}

14. Unlatch and fully raise the acrylic exposure chamber lid of an IES and place the metal basket support/baffle plate and stainless steel mesh exposure basket into the chamber.

CAUTION: A Racal AC3 or Breathe Easy respirator should be in use when operating the IES.

15. Load mice or guinea pigs into the basket and secure the basket lid and cover assembly. Close the chamber lid and press firmly next to each latch until each one snaps with an audible click.

16. Mount a glass nebulizer-venturi to the compressed air and main air-flow fittings located on the front of the instrument. Secure the nebulizer into place with clamps provided, and check to make sure that all joints appear to be seated properly and make a sealed fit.

17. Carefully remove the screw cap above the venturi portion of the nebulizer unit. Inspect the cap for any wear, cracks, or missing gaskets.

18. With a 10-cc syringe fitted with an $18-$ G needle, carefully add $5 \mathrm{ml}$ mycobacteria suspension into the bottom of the venturi. Discard the syringe into the sharps container. Replace the screw cap to the venturi, making sure it is threaded properly and fits tightly.

19. Turn the main power switch to the on position so it is lit, and wait for the control keypad to display the message "Glas-Col Apparatus Co."

20. Turn the UV lamp and program switches to the on position so they are also lit.

The control keypad will display several messages and will then stop with the message "Enter When Ready 0".

21. Press the enter key on the control keypad.

The "Enter Preheat Time 900" message will appear on the keypad display. This indicates that the IES has a preset preheat time of $900 \mathrm{sec}$ (15 min) in which the incinerator used to decontaminate the exhaust air is allowed to raise its core temperature to $790^{\circ} \mathrm{C}$ before the nebulizing cycle begins.

22. Press enter on the keypad to accept the 900 -sec preheat time setting.

The next message is for the nebulizing time. The display will appear with the message "Enter Neb Time 1800," indicating a preset nebulizing time of $1800 \mathrm{sec}$.

23. Enter 2400 (40 min; for mice) or 600 ( $10 \mathrm{~min}$; for guinea pigs) and press enter to set the nebulizing time. If an error is made, press the Esc key and reenter the correct number.

The display for the cloud decay cycle will appear next as "Enter C. D. Time 1800." 
24. Set $2400 \mathrm{sec}$ (for mice and guinea pigs) or $3600 \mathrm{sec}$ (for multi-drug resistant, or MDR, strains of M. tuberculosis) for the cloud decay cycle and press enter to continue.

The final message to appear before the instrument begins operation is "Ent Dec Time 900." This message sets the amount of time in which the UV lamps are turned on and the top surfaces of the basket are exposed to ultraviolet light at $254 \mathrm{~nm}$ for surface decontamination.

25. Press enter to accept the $900-$ sec decontamination time setting.

Once the decontamination time is selected, the IES will begin to cycle sequentially through preheat, nebulizing, cloud decay, and UV decontamination settings for the aerosol challenge of animals within the chamber. The display on the keypad will indicate which cycle is in operation.

26. Once the instrument has started the preheat cycle, check to see that the main air flow meter indicates 60 cubic feet per hour (CFH). If it is not, adjust vacuum control valve until the flow reaches $60 \mathrm{CFH}$.

27. When the nebulizing cycle starts, check that the compressed air flow meter indicates $10 \mathrm{CFH}$. If not, adjust the compressed air control valve until the float in the flow meter indicates $10 \mathrm{CFH}$.

28. When the aerosol infection run is complete, turn off the program, UV lamp, and power switches on the IES.

The instrument will signal the completion of the run with an audible alarm and the message "Process Complete - Remove Specimen" on the keypad.

29. Carefully remove the screw cap on the nebulizer and check the volume of remaining mycobacterial suspension with the aid of a 10-cc syringe fitted with an $18-\mathrm{G}$ needle. Record the volume remaining.

There should be no more than $1.0 \mathrm{ml}$ remaining for infections with mice. Infections with guinea pigs should have 4.0 to $4.5 \mathrm{ml}$ suspension remaining.

\section{Disassemble and clean equipment}

30. Discard the syringe in the sharps container. Remove the nebulizer-venturi carefully from the IES, wrap in paper towel, and place in a stainless steel pan containing 5\% Lysol to a depth of $\geq 5 \mathrm{~cm}$. Place the stainless steel pan in an autoclave bag and autoclave at $121^{\circ} \mathrm{C}$ and $15 \mathrm{psi}$ for $40 \mathrm{~min}$ on slow exhaust.

31. Clean the nebulizer thoroughly with laboratory glassware detergent, rinse well, dry, wrap, and autoclave again to sterilize for future use. Disinfect the fittings where the nebulizer attaches to the IES by wiping with 5\% Lysol followed by $70 \%$ ethanol. Place all cleaning materials in autoclave bags and autoclave.

32. Carefully open the lid, remove the animals from the chamber basket, and return them to their cages.

33. Remove the basket and its support/deflector from the IES chamber, double bag in very large autoclave bags, autoclave, and wash thoroughly with soap and water. 
34. Disinfect the interior surfaces of the IES chamber by wiping them twice with 5\% Lysol and twice with 70\% ethanol. Bag and autoclave all cleaning materials (paper towels).

\section{Analyze results}

35. One day after aerogenic challenge, harvest a statistically significant number of aerogenically exposed animals and verify the uptake of mycobacteria into the lungs (see Basic Protocol 2).

36. Count colonies on the quadrant plates $\sim 20$ days after incubation at $37^{\circ} \mathrm{C}$ (step 12) and calculate the initial titer of the suspension as follows:

$$
\mathrm{cfu} / \mathrm{ml}=\frac{\mathrm{MCC}_{\mathrm{Q}}}{V_{\mathrm{P}} \times \mathrm{DF}_{\mathrm{Q}}}
$$

where $\mathrm{MCC}_{\mathrm{Q}}$ is the mean colony count of replicate countable plate quadrants, $V_{\mathrm{P}}$ is the volume plated per quadrant, and $\mathrm{DF}_{\mathrm{Q}}$ is the dilution factor of the sample in the quadrant.

37. Calculate the mycobacterial load delivered by the IES as cfu $=\mathrm{cfu} / \mathrm{ml} \times \mathrm{DF}_{\mathrm{A}} \times$ $V_{\mathrm{D}}$, where $\mathrm{cfu} / \mathrm{ml}$ is the titer (step 36 ), $\mathrm{DF}_{\mathrm{A}}$ is the dilution factor used to prepare the aerosol suspension (step 7), and $V_{\mathrm{D}}$ is the volume delivered (5 $\mathrm{ml}$ minus the volume remaining in step 29).

\section{Guidelines for Use of the Madison (Generation III) Inhalation Exposure System}

-Exposure of guinea pigs to aerosols of Mycobacterium tuberculosis can be performed under stringent ABL-3 conditions using a Madison (Generation III) infection chamber manufactured by the University of Wisconsin (see Basic Protocol 2). This chamber has undergone very little configuration since the original design in 1970 and there are currently 2-3 dozen chambers in worldwide use today (Selecting the Most Suitable Aerosolization Equipment, Tradeline Inc., 2007). The aerosol chamber consists of a large cylindrical tank which holds a metal aerosol infection basket that contains 18 small individual compartments, each compartment able to house a single guinea pig. The aerosol basket is loaded with guinea pigs and then placed into the Madison aerosol chamber using a cart. The aerosol chamber door is then locked shut with eight latches that secure the door tightly against the machine, preventing air flow from leaking.

The front of the instrument consists of the control panel. This is the power supply chamber system which consists of the power switch, cycle start and stop knobs, emergency shut off button, fan test button, and photohelic unit. The control panel can be opened to check that the time delay relay 1 (TD1) and the second time delay (TD2) are properly set. The TD1 controls the total time of an exposure cycle and should be set to $900 \mathrm{sec} / \mathrm{ON}$ DELAY. The TD2 controls the time that the nebulizer is on and should be set to $300 \mathrm{sec} / \mathrm{INTERVAL}$ DELAY. After the door is closed and latched the photohelic unit should read between 9-13 inches of water to ensure that the proper amount of vacuum is maintained. If the vacuum pressure is lower than 9 inches the exposure cycle will not start. If during a cycle the vacuum pressure exceeds 13 inches then there is a blockage of incoming secondary air. This will sound the alarm and activate the END CYCLE LIGHT. If this occurs the fans will shut off but the nebulizer will continue to work. The cycle can be stopped by pressing the RESET button.

The flow panel is located on the right side of the chamber and contains two flow meters. The right flow meter controls the secondary airflow. This is the air being pumped through the 
system by the vacuum/compressor unit through a series of two HEPA filters at a rate of $\sim 45$ $\mathrm{L} / \mathrm{min}$. The left flow meter indicates the primary airflow. This is the air being channeled through the nebulizer unit and is determined by the pressure regulator located at the center of the flow panel. When the instrument is in operation, compressed air flows through the nebulizer at $\sim 4 \mathrm{~L} / \mathrm{min}$. and this produces a very fine mist of the bacterial suspension, which is then carried by a larger volume of air flowing into the aerosol chamber. The airflow then exits the chamber through two HEPA filters.

A test cycle is run prior to an aerosol infection to be sure that the machine is running properly. During this test cycle no animals are loaded into the chamber. Fifteen $\mathrm{ml}$ of sterilized water in a $20 \mathrm{cc}$ syringe with an $18 \mathrm{G} 1 \frac{1 / 2}{2}$ needle is loaded into a sterile nebulizer jar by unscrewing the plug screw located on the top of the collison nebulizer unit and dispensing the water through the orifice. After dispensing the water into the nebulizer jar refasten the plug screw. Once all doors are properly latched check to see that the proper amount of secondary air flow is $\sim 45 \mathrm{~L} / \mathrm{min}$ and the proper amount of vacuum is maintained. The test run can then be initiated by pressing the CYCLE START button. After starting the cycle check to see that the nebulizer probe is properly functioning. A spray mist coming from three jets will be observed.

If the test cycle runs with no errors then an aerosol infection run can be performed. A new sterilized nebulizer jar is placed on the collision nebulizer unit while the water run nebulizer jar is placed in $5 \%$ Lysol. Ten $\mathrm{ml}$ of inoculum containing $1.0 \times 10^{6} \mathrm{cfu} / \mathrm{ml}$ of M. tuberculosis suspended in sterile saline is added to the nebulizer jar the same way as the sterile water. A metal square spacer is placed at the back of the chamber to prevent the aerosol basket from hitting the fans. The aerosol basket that contains the animals is then loaded into the chamber. The doors are latched, the proper airflow and vacuum pressure gauges are checked, and the CYCLE START button is pressed to initiate the infection run. A cycle will last for 15 minutes. Please note that all interior surfaces of the chamber from the nebulizer to the exit of the HEPA filters are exposed to Mycobacterium tuberculosis during an exposure cycle. When the cycle is complete press the END CYCLE button on the control panel, unlatch the door to unload the aerosol basket containing the animals, then re-latch the door. Finally, carefully unscrew the nebulizer jar containing remnants of the infectious inoculum and place the jar in 5\% Lysol solution. The animals are then carefully unloaded from the basket and placed back into their correct cage. If more that one infectious aerosol cycle needs to be performed repeat the above process.

Once all infectious cycles are complete a final water run is performed. This is similar to the initial water run except prior to adding a new sterile nebulizer jar the probe is carefully dabbed with a Wypal soaked with 5\% Lysol followed with a Wypal soaked with 70\% ethanol. Also, $20 \mathrm{ml}$ of sterile water is added to the nebulizer jar instead of $15 \mathrm{ml}$. During this water run the aerosol basket can be loaded into an autoclave bag to be sterilized by autoclaving. The cart that holds the aerosol basket is then properly wiped down with first a $5 \%$ Lysol solution followed with a $70 \%$ ethanol solution.

Additional Note: Over the past few years there have been accidents reported with the Madison Chamber, which has diminished confidence in its use. We can only speak for ourselves but our experience has been that this is a fine instrument if used properly. Moreover, it has certain advantages to other systems such as "nose-only" devices. Some laboratories, we note, have attached the Madison chamber itself directly into the side of Class-II cabinets for extra safety. 


\section{BASIC PROTOCOL 2 \\ AEROSOL INFECTION OF GUINEA PIG WITH MYCOBACTERIA}

Pulmonary tuberculosis in guinea pigs has multiple similarities to the disease in humans. It has long been considered the gold standard small animal model for vaccine testing, and it is beginning to be used to evaluate chemotherapy (Lenaerts, 2008; Ordway 2008; Williams, 2009; Ordway 2010). All airborne infections of animals using Mycobacterium tuberculosis must be performed in an appropriate ABL-3 laboratory equipped with a Class II biosafety cabinet (see Strategic Planning).

The parameters given here are intended only to serve as a guide, and the individual researcher should test the operation of the IES empirically by doing a series of experimental aerosol challenges at different concentrations of bacilli in order to establish the individual differences that may exist between instruments.

\section{Materials}

Class II Biosafety cabinet

Guinea pigs to be infected

$1.5-\mathrm{ml}$ frozen stock suspensions of M. tuberculosis $\left(5.0 \times 10^{7}\right.$ to $5.0 \times 10^{8} \mathrm{cfu} / \mathrm{ml}$; see Support Protocol)

$5 \%(\mathrm{v} / \mathrm{v})$ Lysol

$70 \%$ (v/v) ethanol

Sterile $\mathrm{H}_{2} \mathrm{O}$

Paper towels

$7 \mathrm{H} 10$ or $7 \mathrm{H} 11$ agar quadrant petri plates (see recipe)

Pan sonicator

Absorbent hood blotters with plastic backing

Wash bottles for 5\% Lysol and 70\% ethanol

Stainless steel pipet boat with cover

Disposable surgical gown

1-cc disposable tuberculin syringes fitted with 261/2-G needles (VWR)

50-ml conical polypropylene centrifuge tube (Fisher)

5-ml conical polypropylene centrifuge tube (Fisher)

$12 \times 125-\mathrm{mm}$ culture tubes with caps

1.0-ml disposable serological pipets (VWR)

Resealable polypropylene bags

RACAL AC3 or PAPR, Breathe Easy respirator unit (Lab Safety supply)

Glass nebulizer-venturi (Glas-Col), sterilized and wrapped

10-cc disposable syringes fitted with $18-\mathrm{G}$ needles (VWR)

P1000 micropipette (VWR)

P1000 micropipette blue tips (VWR) 
24 well flat bottom plate (Fisher)

Tupperware container

Autoclaved glass nebulizer jars (Precision Glass)

Timer (VWR)

Madison infection chamber

Infection basket(s) (Glas-Col)

Prepare mycobacteria aerosol suspension (see Basic Protocol 1)

Confirm titer of starting suspension (see Basic Protocol 1)

Infect animals aerogenically

1. Begin the test run in the Madison chamber (15 minute cycle):

CAUTION: A Racal AC3, PAPR or Breathe Easy respirator should be in use when operating the IES.

2. Dispense the $15 \mathrm{ml}$ of $\mathrm{ddH}_{2} \mathrm{O}$ into the autoclaved glass nebulizer jar by removing the plug screw (Figure 1), unsheathing the needle, and placing the needle tip in through the orifice to rest against the side of the jar (so as not to create any aerosols when dispensing).

3. After dispensing the $\mathrm{ddH}_{2} \mathrm{O}$ into the jar, re-fasten the plug screw!

4. For the test run only, unlatch the Control Box lid (Figure 2A), and check that the time delay relay, TD1, is set to $900 \mathrm{sec} / \mathrm{ON}$ DELAY, and that the second time delay, TD2, is set to $300 \mathrm{sec} / \mathrm{INTERVAL} \mathrm{DELAY} \mathrm{(Figure} \mathrm{2B).}$

5. Close/latch the Control Box lid, and supply power to the chamber system by depressing the outlet switch (white button on power strip), this powers the compressor/vacuum pump unit.

6. Check for the proper amount of airflow into the system (secondary air, $\sim 45 \mathrm{~L} /$ $\mathrm{min}$ ) indicated on the flow meter on the right side of the flow panel (Figure 3). Also, be sure to check the Photohelic unit (Figure 2A) that the proper amount of vacuum is being maintained (should read 9-10 inches of $\mathrm{H}_{2} \mathrm{O}$ ).

7. Turn on the Control Box "Power" switch by turning clockwise.

8. Press the Nebulizer "Test" button to check for the proper airflow into the nebulizer ( 4 L/min) as indicated on the flow meter at left on flow panel (Figure 3).

9. Unlatch the chamber door (8 latches around the perimeter) and open the door to visualize the mixing fans.

10. Test the mixing fan(s) operation by depressing the Fan "Test" button on the Control Box.

11. If everything is operational, re-seal the airtight door with all 8 latches.

12. Initiate the test run by depressing the "Cycle Start" button on the Control Box (Figure 2A).

13. With a pen, log both the reading on the primary airflow meter into nebulizer left side of flow panel) \& the reading on the pressure gauge Figure 3) beneath the regulator into the log book which is kept on the cart beneath the chamber. 
14. Also, before leaving the room, be sure that the nebulizer is fully functional by checking for spray coming out of each of the 3 jets of the nebulizer probe.

15. Lastly, post the "Infection in progress Do Not Enter" sign over the door window.

16. Next, place the stainless steel container (or containers, depending on how many aerosol runs are required) and fill with a 5\% Lysol solution. Place this/these next to the aerosol machine (all used "used" nebulizer jars will be placed into a container of this sort).

17. After the M. tuberculosis has thawed, place some absorbent bench-top paper inside the biosafety cabinet, don a disposable surgical gown, double glove, and fill one $50 \mathrm{ml}$ conical tube with the $5 \%$ Lysol solution ( $25 \mathrm{ml})$.

If two or more staff members are present, while the inoculum is being prepared, the other staff member(s) can load the guinea pigs to be challenged into the infection basket. This can be performed for the first two aerosol runs inside the guinea pig housing rooms (since both infection baskets have been autoclaved). However, once each basket has went through one infection cycle, for ALL other runs the guinea pigs need to be loaded into the infection baskets (as well as unloaded after the infection cycle) from the chamber room into their cages that are to go no further than the chamber ante-room. After all guinea pigs have been loaded/unloaded the cages on the cage cart/rack in the anteroom are to be removed and placed back into the housing room or temporarily stored in the hallway until the cycle is completed.

18. Then, pipette $11 \mathrm{ml}$ of sterile $\mathrm{ddH}_{2} \mathrm{O}$ (using a $10 \mathrm{ml}$ pipette) into an additional $50 \mathrm{ml}$ conical tube and close the cap on the "dilutent tube" and stand in the tube rack.

19. Spray the top of the M. tuberculosis vial with $70 \% \mathrm{EtOH}$.

20. Fit the $1 \mathrm{cc}$ syringe with $26 \mathrm{G}^{1} \frac{1}{2}$ needle, insert needle into the vial, \& invert vial.

21. Pull bacteria in and out of syringe at least ten to twenty times do not froth.

22. Pull approximately $1 \mathrm{ml}$ into the syringe; then, turn the bottle upright and pull approximately $100 \mu \mathrm{l}$ of air into the syringe (so that the vial does not "spit" when needle is removed); withdraw needle.

23. Slowly dispense the $1 \mathrm{ml}$ into a $5 \mathrm{ml}$ tube so as not to create an aerosol.

24. In a second $5 \mathrm{ml}$ Falcon tube, perform the necessary dilution(s) to arrive at the working stock concentration needed to place into $11 \mathrm{ml}$ of sterile $\mathrm{ddH}_{2} \mathrm{O}$ such that the final concentration is $1 \times 10^{6} \mathrm{CFU} / \mathrm{ml}$, and that upon transferring this aliquot into the $11 \mathrm{ml}$ of dilutent this dilution does not exceed $1 / 10$.

25. Remove cap from the dilutent $50 \mathrm{ml}$ conical tube, and with the P1000 micropipette pull the pre-determined amount of bacteria into a P1000 blue tip from the working stock and dispense into the dilutent tube by placing the needle tip just below the meniscus of dilutent, and slowly adding the bacteria to the 11 ml volume of $\mathrm{ddH}_{2} \mathrm{O}$.

26. Discard the P1000 tip CAREFULLY into the 5\% Lysol-containing pipette boat.

27. With the P1000, dispense $900 \mu$ into 7 consecutive wells on a 24-well plate.

28. With a $10 \mathrm{ml}$ pipette, mix the "inoculum" by repetitive pipetting. 
29. With the P200, dilute $100 \mu$ l of the "inoculum" into the first well on the 24-well plate, and serially dilute across the remaining 6 wells.

30. Using a $20 \mathrm{cc}$ syringe fitted with a $18 \mathrm{G} 1 \frac{1 / 2}{2}$ needle, pull $10 \mathrm{ml}$ of the "inoculum" from dilutent tube into the syringe.

31. Plate $100 \mu \mathrm{l}$ from each well on the 24 -well plate $\left\langle 10^{-1}\right.$ thru $10^{-7}$ dilutions $\rangle$ onto two $7 \mathrm{H} 11$ quad plates and place into the $37^{\circ} \mathrm{C}$ incubator.

32. With the same 20cc syringe, transport the "Inoculum"-filled syringe (along with a timer) into the hallway inside the Tupperware container.

Note: Put on the A Racal AC3, PAPR or Breathe Easy respirator should be in use when operating the IES.

33. Transport the container with the syringe (and the autoclaved nebulizer jars if haven't done so already) into the chamber room.

34. When the "End cycle" indicator sounds for the test run, press "Reset" on the control box and take out 1 of the autoclaved nebulizers from their individual containers.

35. Unscrew the nebulizer jar used for the test run from the apparatus, and replace with a fresh autoclaved nebulizer jar (place the "used" nebulizer jar into the Lysol-containing stainless-steel container).

36. After the nebulizer jar is screwed tight, remove the plug screw and repeat Step 2 and 3 with the syringe containing the $10 \mathrm{ml}$ of "inoculum".

37. Pull $\sim 15 \mathrm{ml}$ of $5 \%$ Lysol (from the stainless steel container) inside the syringe and place back into the stainless-steel container.

Be sure to re-fasten the plug screw before proceeding.

38. Load the guinea pigs (inside the infection basket) into the chamber by aligning the cart to the opened chamber door, latching the lock-pin, and sliding the basket into the main cylinder of the chamber.

Be sure that the spacer is in place at the posterior (the spacer should be placed between the rear mixing fans and the infection basket) of the chamber before re-latching the chamber door.

39. Re-latch the door, and be sure that ALL the 8 latches are fastened on the door so as to create the necessary air-tight seal.

40. Re-check for the proper amount of airflow being channeled through the chamber $(\sim 45 \mathrm{~L} / \mathrm{min})$. Also, be sure to check that the vacuum gauge reads $\sim 9-10$ inches of $\mathrm{H}_{2} \mathrm{O}$ (after opening/closing the chamber door this may take a couple of minutes).

41. Initiate the cycle by depressing the "Start" button, and set $15 \mathrm{~min}$ on the timer.

42. Again, be sure to check the 3 jets on the nebulizer probe for proper spray/ dispersion before leaving the room.

43. Again, be sure that the "Infection in progress Do Not Enter" sign is visible over the door window.

44. Leave the room.

45. Once the "End cycle" indicator light/alarm sounds, depress the "Reset" button.

46. Open the chamber door and remove the infection basket. 
47. Transfer each of the infected guinea pigs back into their cages by mobilizing the entire cage rack (or cart will do if only a few guinea pigs are being aerosolized) into the ante-room, and transferring each of the guinea pigs from the aerosol basket into their cages.

48. For multiple runs, re-mix the inoculum inside the $5 \mathrm{ml}$ Falcon tube, and repeat Steps 25 thru 48.

\section{Disassemble and clean equipment}

49. Place the "inoculum" syringe(s) into a sharps container.

50. After the final infection run, carefully unscrew the nebulizer jar from the apparatus, liberally wrap in paper towels, and place into the 5\% Lysol solution inside the stainless-steel autoclavable container, and place the lid on the container.

51. Thoroughly, but gently wipe the entire stainless-steel nebulizer probe with paper towels doused in 5\% Lysol.

Do not press the paper towels too hard over the nebulizer probe. There are minute holes that paper towel filaments can plug and, thus, block the nebulizer jets.

52. Repeat Step 51 with a paper towel stack doused in $70 \% \mathrm{EtOH}$.

53. Pour approximately $20 \mathrm{ml}$ of $\mathrm{ddH}_{2} \mathrm{O}$ (from a sterile $50 \mathrm{ml}$ conical tube) inside an additional autoclaved nebulizer jar and screw into the apparatus.

54. Check for the proper amount of airflow being channeled through the chamber as before $(\sim 45 \mathrm{~L} / \mathrm{min})$. Also, be sure to check that the vacuum gauge reads $\sim 9-10$ inches of $\mathrm{H}_{2} \mathrm{O}$.

55. Initialize the "Cleaning run" by depressing the "Start" button on the Control box.

56. Following the "Cleaning run", turn off all switches.

57. Replace the nebulizer jar with the final autoclaved nebulizer jar.

58. Place the "used" jar into the $5 \%$ Lysol solution.

59. Close the lid to the container, place into a large biohazard bag, and mark "FRAGILE - glass nebulizer jars".

60. Remove the infection basket(s) from the cart(s), double bag with the X-large biohazard bags, and seal with autoclave tape.

61. Open the chamber door, and wipe inside of chamber apparatus with Lysol (5\%); repeat process with $70 \% \mathrm{EtOH}$.

62. Repeat Step 53 on the basket cart.

63. Sweep up floor, and dispose of any debris from animal cages,.

64. Remove the "Infection in progress Do Not Enter" sign from the door.

65. Leave the room, replace PAPR.

66. Nebulizer/aerosol baskets need autoclaving.

\section{Analyze results (see Basic Protocol 1)}




\section{ALTERNATE PROTOCOL INTRAVENOUS INFECTION OF MICE WITH MYCOBACTERIA}

This protocol is a modified description of the intravenous inoculation of mice via the lateral tail vein except that strict adherence to safety guidelines for handling equipment, reagents, and mice must be observed. This infection route, used at the recommended dose, established a sublethal systemic infection that is a suitable model for study of the cellular immune response.

The proper handling and restraint of mice needs to be mastered before any attempts are made at intravenous inoculation with virulent strains of M. tuberculosis. The experimenter needs to be fully cognizant of inherent dangers such as accidental needle stick or aerosol exposure when performing this technique. It is extremely important that one not be distracted when inoculating mice intravenously with $M$. tuberculosis and that the task be done with a very methodical approach.

CAUTION: The intravenous infection of mice with M. tuberculosis should be done in an appropriate ABL-3 laboratory as described above (see Strategic Planning). In addition, double disposable gloves should be worn to prevent accidental exposure in case an outer glove tears during animal handling. A full face shield should be worn to prevent accidental exposure from injectate inadvertently spraying back during injection. A simple plastic face shield or visor is probably sufficient, but a powered positive-pressure air-purifying respirator helmet (e.g., RACAL AC3, PAPR or Breathe Easy) is strongly recommended.

\section{Additional Materials (also see Basic Protocol 1)}

PBS, sterile (VWR)

15-ml conical polypropylene centrifuge tubes (Fisher)

Face shield with respirator (optional substitute for RACAL AC3, PAPR or Breathe Easy respirator units)

Equipment for mouse restraint and intravenous injections

\section{Prepare mycobacterial i.v. suspension}

1. Prepare the work space and thaw and dissociate a stock mycobacterial culture as described (see Basic Protocol 1, steps 1 to 6).

2. Remove a volume of mycobacterial suspension with the syringe and carefully dispense down the side of a $15-\mathrm{ml}$ conical polypropylene centrifuge tube containing sterile saline or PBS to achieve $0.2 \mathrm{ml}$ per mouse at $5 \times 10^{5} \mathrm{cfu} / \mathrm{ml}$. Place the syringe in the sharps container for disposal.

The standard dose for M. tuberculosis via the intravenous route is $1.0 \times$ $10^{5} \mathrm{cfu}$ per mouse, delivered in a volume of $0.2 \mathrm{ml}$.

3. Confirm the titer of the starting suspension (see Basic Protocol 1, steps 8 to 12).

\section{Infect mice intravenously}

4. Place a cage containing the mice to be injected under a heat lamp to allow gentle warming in order to promote vasodilation.

It is essential to observe the mice while they are warming and ensure that they do not become heat stressed while under the lamp. If mice 
appear to be agitated or heat stressed, remove the cage immediately from beneath the lamp.

5. While the mice are warming, secure an appropriate mouse restrainer to the laboratory bench.

6. In the biological safety cabinet, fill a $1-c c$ tuberculin syringe fitted with a $261 / 2-G$ needle with $M$. tuberculosis suspension. Carefully remove any air bubbles from the syringe by holding the syringe up at a $45^{\circ}$ angle and gently dispensing the suspension back into the test tube, taking care not to create an aerosol.

It is important to remove air from the syringe as it can cause emboli if not removed.

7. When the mice have become sufficiently warm, cannulate the lateral tail vein as described in UNIT 1.6.

It is desirable to make the first attempt at injection as close to the tip of the tail as possible, so that a second attempt, if necessary, can be safely made more proximally on the opposite vein.

8. Slowly inject $0.2 \mathrm{ml}$ suspension.

If the needle is properly inserted, there should be no resistance to inoculum flow and no formation of blebs or local induration. If these problems are encountered, remove the needle and attempt to cannulate the opposite lateral vein.

CAUTION: NEVER force the syringe if the vein was missed, as this may result in a potential aerosol of the bacterial suspension should the needle hub dislodge from either the syringe or the tail.

9. Carefully withdraw the needle and use gauze to apply digital pressure at the injection site to maintain hemostasis.

10. Place the injected mouse in a spare cage and continue injections with additional animals. When injections are complete check the animals for normal behavior and then return them to their housing location.

11. Disinfect the biological containment cabinet after use. Double bag culture tubes, stock vials, and the pipet boat in autoclave bags and tape with heat-sensitive autoclave tape.

12. One day after intravenous challenge, harvest a statistically significant number of intravenously exposed mice and verify the uptake of mycobacteria into the lungs (see Basic Protocol 3).

13. After $\sim 20$ days incubating titer plates (see step 3 ), calculate the initial titer of the stock suspension (see Basic Protocol 1, step 36) and then calculate the mycobacterial load using the dilution factor of the i.v. suspension (see step 2 above).

\section{BASIC PROTOCOL 3 \\ NECROPSY METHODS FOR ANIMALS EXPERIMENTALLY INFECTED WITH MYCOBACTERIA}

The removal of organs for determination of bacterial load, organ pathology, cell culture, analysis of cell populations by flow cytometry, PCR analysis for cytokine/chemokine message, or histological analysis are the most common approaches following mycobacterial 
infection in animal model systems. This protocol describes the procedure for harvesting the spleen, liver, and lungs from the mouse to determine mycobacterial load. It should be noted that the techniques described are applicable to the guinea pig and rabbit models with minor modifications.

CAUTION: All processing of tissues derived from animals infected with Mycobacterium tuberculosis must be done in an appropriate ABL-3 laboratory equipped with a Class II biosafety cabinet (see Strategic Planning). All homogenization of Mycobacterium-infected tissues should be done in a Class II Biosafety cabinet with an attached glove box, which protects the user from the significant aerosols generated by tissue grinding and disruption techniques.

\section{Materials}

Mycobacterium-infected animals (see Basic Protocol 1 or Alternate Protocol)

$70 \%(\mathrm{v} / \mathrm{v})$ ethanol

Sterile saline: $0.85 \%(\mathrm{w} / \mathrm{v}) \mathrm{NaCl}$

$\mathrm{CO}_{2}$

$5 \%(\mathrm{v} / \mathrm{v})$ Lysol

Paper towels

$7 \mathrm{H} 10$ or $7 \mathrm{H} 11$ agar quadrant petri plates (see recipe)

Dissection board (VWR)

Dissection instruments, sterile (medium dissection scissors, tissue forceps, small iris scissors, iris forceps, small toothed forceps, surgical scissors, dissecting pins)

Sterile polypropylene $250-500 \mathrm{ml}$ beaker

10- or 40-ml homogenization tubes with foam stoppers (Glas-Col)

Class II multihazard glove box (Labconco) fitted with a variable-speed homogenizer drive assembly (motor) actuated via a foot pedal (Glas-Col)

Pestle packs: homogenization pestles with stainless steel shanks and Teflon pestle heads, bagged in instrument sterilization packs (10 pestles per pack; Glas-Col)

Styrofoam freeze chest (VWR)

Stainless steel pestle boat with lid (VWR)

Stainless steel pipet boat (VWR)

Absorbent hood blotters with plastic backing

1.0-ml sterile disposable serological pipets with $0.1-\mathrm{ml}$ graduations

$12 \times 125-\mathrm{mm}$ culture tubes with caps (Pyrex)

Mechanical pipetting device (e.g., Pipet-Aide)

Resealable polypropylene bags (VWR)

$37^{\circ} \mathrm{C}$ agar plate incubator (VWR)

\section{Remove organs}

1. Sacrifice mice in a humane manner. Euthanize a M. tuberculosis-infected mouse by $\mathrm{CO}_{2}$ inhalation exposure system, dry ice in a jar or another humane manner. 
2. For guinea pigs anesthetize an animal to a very deep level use a cocktail of ketamine and of xylazine in a $1 \mathrm{ml}$ syringe with a 26 gauge needle. The concentration of the drugs are based on the individual body weight of each animal. The cocktail is injected IM in the back of the thigh. Place the guinea pig on its back in its cage and once it is not able to turn over euthanize the animal. Transfer the animals to the hood and place them on clean, dry, absorbent paper on the necropsy board. To euthanize use a $1 \mathrm{ml}$ solution of a 1:1 dilution of Beuthanaisa-D Special (active ingredients: $390 \mathrm{mg}$ pentobarbital sodium, $50 \mathrm{mg}$ phenytoin sodium) and sterile saline given in a $3 \mathrm{ml}$ syringe with a $20 \mathrm{~g}$ needle injected into the heart. Or use a $3 \mathrm{ml}$ solution of a 1:1 dilution of Beuthanaisa-D Special and sterile saline given in a $3 \mathrm{ml}$ syringe with a 18 gauge 1.5 inch needle injected IP. Using a wash bottle thoroughly wet the fur with $70 \%$ ethanol to sterilize the area and reduce the possibility of fouling HEPA filters with animal dander.

3. In a Class II biosafety cabinet, place the animal on its back on clean, dry, absorbent paper towels covering a dissection board.

4. Wet the fur with $70 \%$ ethanol to sterilize the area and reduce the possibility of contamination from loose fur while making incisions. Place sterile dissection instruments into a beaker containing $70 \%$ ethanol.

5. Pin the hind legs of the mouse to the dissection board and make a midline incision with medium-sized dissection scissors. A guinea pig is generally too large to pin and is placed on its back.

6. Retract the mouse skin above the head and below the thighs by pulling it with gloved fingers. Pin down the retracted skin to immobilize the animal to the dissection board.

7. Grasp the lower medial area of the mouase peritoneal wall just above the area near the urinary bladder with the iris forceps and make a small (3- to 4-mm) incision with small iris scissors.

8. For the guinea pig while grasping the skin over the chest with forceps, take the curved scissors and cut away the skin from the chest to expose the ribcage. At this stage the animal is still not considered infectious as all the organs are contained. Once the peritoneum integrity is compromised the animal must be treated as infectious. With the straight dissecting scissors, cut a notch at the tip of the sternum and continue cutting laterally on either side until the animal is exposed below the diaphragm. Go far enough down so you can have access to the spleen. Going underneath the tip of the sternum, punch a small hole in the diaphragm and allow the lungs to pull away from the diaphragm (so you don't put any holes in the lungs). You can then use the scissors to cut the rest of the diaphragm away from the rib cage and begin removing the ribs and chest plate from the animal.

9. While still grasping the lower peritoneum, make two lateral incisions toward the axillary region creating a $\mathrm{V}$-shaped cut through the peritoneum. Take care not to cut the bladder or the intestines. Reflect the peritoneal wall over the thoracic area.

10. For removal of spleen as and place the spleen in a 10-ml (mouse) or 40-ml (guinea pig) Glas-Col homogenization tube containing $4.5 \mathrm{ml}$ sterile saline and cover with a foam stopper. 
Alternatively, place the spleen in several milliliters of tissue culture medium in a tissue culture tube if leukocytes will be isolated.

11. For removal of liver: With small toothed forceps, grasp underneath the right lateral lobe of the liver to a point across the inferior vena cava. Use iris scissors to gently flip these lobes back over the forceps to grasp these lobes as well as the common bile duct. With a firm hold on these tissues, make an incision with the scissors between the liver and the diaphragm and cut the inferior vena cava, freeing the liver. Extricate the liver as one organ with a quick but gentle upward motion. Place the liver in a 10-ml (mouse) or 40-ml (guinea pig) Glas-Col homogenization tube containing $9.0 \mathrm{ml}$ sterile saline and cover with a foam stopper.

12. For removal of lungs: Make an incision through the thoracic cavity with surgical scissors and reflect the thoracic wall, so that the lungs are readily visible on either side of the heart. With small toothed forceps, grasp the bronchial tree close to the heart and cut the lung lobes away. Place the lungs in a 10-ml (mouse) or 40-ml (guinea pig) Glas-Col homogenization tube containing $9.0 \mathrm{ml}$ sterile saline and cover with a foam stopper.

\section{Homogenize tissues}

13. Turn on the blower, power, and light switches of a Class II biosafety glove box and make sure everything is in proper working order. Inspect the gloves carefully before each use to determine if they are free of cracks and holes that could compromise the integrity of the chamber.

The main blower motor requires $\geq 5$ min to get up to proper speed and establish a negative-pressure environment within the glove box cabinet.

14. Place sterile pestle packs in a Styrofoam freeze chest with 5 to $10 \mathrm{lb}$ (2.3 to 4.5 $\mathrm{kg})$ dry ice to chill.

The authors typically chill the pestle packs on dry ice overnight in a $-20^{\circ} \mathrm{C}$ freezer; however, they should be sufficiently cold after $2 \mathrm{hr}$ in dry ice.

15. Fill a stainless steel pestle boat with $\sim 7.5 \mathrm{~cm}$ of $5 \%$ Lysol. Open the outer access door of the air lock entry port for the glove box chamber and place the pestle boat and chilled pestle packs inside the air lock chamber. Close and secure the outer door of the air lock. With hands in the glove ports, open the inner access door of the air lock entry port, remove the pestle boat and pestles from the air lock, and place them within the glove box chamber. Close the inner access door.

16. Transfer a test tube rack with the homogenization tubes containing organs through the air lock as described above.

17. With hands in glove ports, carefully remove foam stoppers from the homogenization tubes and place them on a paper towel located within the glove box chamber. Carefully open the pestle packs and place the chilled pestles into the homogenization tubes, taking care not to splash or spill the tube contents.

It is recommended that homogenization be done in groups of five to ten tubes with chilled pestles. Pestles begin to warm up once they are placed in the tubes, and since the tolerances of the Glas-Col homogenization tubes are quite tight, the pestle may jam in the tube during the grinding process. 
18. For mice remove one homogenization tube from the test tube rack and attach the shaft of the pestle into the chuck of a homogenizer drive assembly and secure. Grasp the homogenization tube firmly with both hands and actuate the grinder via the foot pedal. While the pestle is rotating, slowly move the homogenizing tube up and down three to four times to thoroughly homogenize the organ.

It is essential to have a firm grasp of the homogenization tube while performing this technique as the pestle will rotate in the tube at rather high rpm. If the tube is not securely held the contents will splatter within the glove box chamber and create a substantial aerosol.

19. Carefully remove the pestle and gently place in the pestle boat containing Lysol. Return the tube to the test tube rack and repeat this operation until all tubes have been thoroughly homogenized.

20. For guinea pigs remove the homogenization tubes one a time from the test tube rack, remove the foam stopper and use the tissue tearer to homogenize each organ. After the organ is ground up, replace the foam stopper and return the tube to the rack. Then run the tissue tearer through the $70 \%$ ethanol tube first, then one of the sterile saline tubes and then through the last sterile saline tube. You need to wash the tissue tearer between each organ.

21. Recap tubes with the foam plugs. Wait 10 to $15 \mathrm{~min}$ before removing from the glove box to allow the decay of any aerosol that may have developed during homogenization.

22. Transfer the rack of tubes through the inner access door of the air lock and secure this door. Wipe down the interior surfaces of the glove box with $5 \%$ Lysol followed by $70 \%$ ethanol. Double bag all paper towels used in cleaning prior to removal from the glove box. Also cover the pestle boat with a lid and also double bag for autoclaving.

23. Open the outer access door of the glove box and transfer the tubes to the Class II biosafety cabinet.

The tissue homogenates are ready for serial dilution and plating on $7 \mathrm{H} 10$ or $7 \mathrm{H} 11$ agar plates.

\section{Culture tissue homogenates}

24. Disinfect the biosafety cabinet with 5\% Lysol followed by $70 \%$ ethanol and place all cleaning materials into autoclave bags for autoclaving.

25. Fill a stainless steel pipet boat with $5 \%$ Lysol to a $2.5-\mathrm{cm}$ depth and place toward the rear of the cabinet.

26. Using a 1.0-ml disposable serological pipet, transfer $0.5 \mathrm{ml}$ tissue homogenate to a $12 \times 125-\mathrm{mm}$ culture tube containing $4.5 \mathrm{ml}$ sterile saline. Continue for a total of four to six 10-fold serial dilutions for each homogenate. Dispose of these and all used pipets in the pipet boat containing Lysol.

The total number of dilutions depends on the expected mycobacterial loads within the organs and the time points postinfection.

27. Apply $0.1 \mathrm{ml}$ of each dilution to one quadrant of a $7 \mathrm{H} 10$ or $7 \mathrm{H} 11$ agar quadrant petri plate using a mechanical pipetting device.

Any drips or spills that occur during the plating process should be immediately decontaminated with 5\% Lysol. 
28. Place plates in resealable polypropylene bags and transfer to a $37^{\circ} \mathrm{C}$ incubator.

29. Double bag all materials used in plating (e.g., dilution tubes, homogenization tubes, pipet boats, test tube racks), remove from the hood, and place in a large pan for autoclaving out of the ABL-3 facility.

30. Disinfect the interior work surfaces of the hood with $5 \%$ Lysol followed by $70 \%$ ethanol. Dispose of all paper towels in autoclave bags.

31. Incubate the plates at $37^{\circ} \mathrm{C}$ in the dark for $\sim 3$ weeks.

\section{Alternative tissue homogenate plating method}

24. Dispense $800 \mathrm{ul}$ of sterile saline into 24 well plates using an automatic pipettor; leave the first row empty.

25. Dispense undiluted homogenate into the first row of a 24 well plate using a $1 \mathrm{ml}$ pipette. Discard the pipette in the pipette boat as described above.

26. Using a multi-channel and sterile tips (with a wide bore to prevent blockage) carefully make serial 200ul dilutions across the plate. Change tips with every row as mycobacteria are very sticky and will remain in the tips resulting in carry-over and inaccurate dilutions. Dispense tips into the pipette boat.

27. Using a pipette, dispense 100ul of each homogenate dilution onto the agar plates. This procedure should be carried out immediately after the dilutions have been prepared as over time mycobacteria will stick to the plates and dilutions will not be accurate.

28. At the completion of a single 24 well plate, dispense 5\% Lysol into each well using a pipette. A wash bottle must not be used, as this will generate an aerosol. Place plate inside a small autoclave bag, seal, and place into a pan for disposal. Wipe multi-channel with 5\% Lysol and remove from the hood. Ensure that no homogenate has entered the barrel of the pipette. In the event that this occurs, dismantle and clean pipette.

29. Double bag all materials used in plating (e.g., dilution tubes, homogenization tubes, pipet boats, test tube racks), remove from the hood, and place in a large pan for autoclaving out of the ABL-3 facility.

30. Disinfect the interior work surfaces of the hood with $5 \%$ Lysol followed by $70 \%$ ethanol. Dispose of all paper towels in autoclave bags.

31. Incubate the plates at $37^{\circ} \mathrm{C}$ in the dark for $\sim 3$ weeks.

32. Determine the bacterial load within the organ using the following formula:

$$
\text { cfu/organ }=\frac{\mathrm{CC}_{\mathrm{Q}} \times V_{\mathrm{H}}}{V_{\mathrm{P}} \times \mathrm{DF}_{\mathrm{Q}}}
$$

where $\mathrm{CC}_{\mathrm{Q}}$ is the colony count in one quadrant, $V_{\mathrm{H}}$ is the total volume of the homogenate, $V_{\mathrm{P}}$ is the volume plated onto the quadrant, and $\mathrm{DF}_{\mathrm{Q}}$ is the dilution factor of sample in the quadrant.

As an example, suppose that a quadrant contains 26 colonies $\left(\mathrm{CC}_{\mathrm{Q}}\right)$ of a sample that was plated in a $0.1-\mathrm{ml}$ volume $\left(\mathrm{V}_{\mathrm{P}}\right)$ and diluted by $1.0 \times 10^{-3}\left(\mathrm{DF}_{\mathrm{Q}}\right)$ from an original homogenate volume of $10.0 \mathrm{ml}\left(\mathrm{V}_{\mathrm{H}}\right)$. Using the above formula the bacterial load in $\mathrm{cfu} /$ organ for this sample would be $(26 \times 10.0) /\left(0.1 \times 1.0 \times 10^{-3}\right)=2.6 \times 10^{6}$ 


\section{BASIC PROTOCOL 4}

\section{FOLLOWING THE COURSE OF INFECTION}

Daily animal observation during mycobacterial infection is a necessary part of animal husbandry. When mice and guinea pigs show certain clinical symptoms indicative of morbidity (which can vary dependant on the mycobacterial strain virulence, vaccination or drug treatment procedures), a score can be given to those symptoms indicating severity of disease progression and animals under authority of the facility Veterinarian can be euthanized.

To achieve this, simple Karnovsky scales can be generated. Animals should be scored in terms of general behavior, feeding habits, and weight gain or loss. In addition, the veterinary staff should be alerted to various clinical problems such as ulcerative dermatitis (mice often fight to establish pecking orders), or tumors [sometimes a problem with certain inbred strains). Torticollis, in which the animal is actively spinning or rolling, is sometimes seen. Other symptoms may be seen depending on the nature of the study.

Information such as clinical scores, daily weights, and body temperatures can provide useful information for evaluating animal disease progression. The recent invention of temperature sensitive chips which can be inserted beneath the skin of the animal and monitored easily using a scanner (Bio Medic Data Systems, Inc. Seaford, Delaware) has made this task easy.

Disease progression can be monitored by evaluating the existing organ pathology at different stages of infection. Mice are the most widely used small animal model because of the broader availability of immunological reagents, and of inbred and genetically engineered strains with well defined genotypes (Basaraba, 2008; Ordway 2007). The pulmonary granulomatous response to $M$. tuberculosis in the mouse differs from that in the guinea pig or human. The major difference is the lack of early central caseating necrosis in primary pulmonary lesions of immunologically intact mice. In addition, due to the smaller organ size it is difficult to discriminate between primary and secondary lesions in the organs. Generally the disease progresses in five stages (Rhoades, 1997) which are based on the extent of granulomatous involvement, the cell types present, the degree of lymphocyte organization, and the presence of destructive sequelae such as airway epithelium erosion and airway debris. Many of these parameters can be used to give an overall group ranking or lesion score based on histopathological assessments by a qualified veterinary pathologist (Orme, 2007; Basaraba, 2008).

The disease that develops in the guinea pig following aerosol exposure to M. tuberculosis can be divided into acute, subacute and chronic stages of infection based on the pattern of bacterial growth and dissemination, as well as patterns of pulmonary and extra-pulmonary pathology (Turner, 2003; Basaraba, 2006; Basaraba, 2006). During acute infection, there is an initial 3 day lag in bacterial growth, followed by an approximately 2 week period of rapid bacterial proliferation in the lung and draining lymph nodes. The acute stage is also characterized by progression of granulomatous inflammation and necrosis in the primary granuloma lesion of the lung and draining mediastinal lymph nodes. The subacute or bacillemic phase from 2 to 4 weeks, is characterized by the emergence of a stationary phase of bacterial replication in the lung and lymph nodes. During the subacute phase, the most severe inflammation within the primary lesion begins to subside but not before it has replaced a significant proportion of the normal tissue, particularly in the draining lymph nodes (Turner, 2003; Basaraba, 2006). Importantly in this subacute stage, infection is established in multiple extra-pulmonary sites such as the spleen and liver by hematogenous dissemination of bacilli. Concurrent with bacillemia and exponential bacterial growth in extra-pulmonary sites, there is re-infection of the lung by the hematogenous dissemination. 
Finally, the chronic stage is characterized by continued bacterial replication in extrapulmonary tissues but with either stationary or a gradual increase in bacterial numbers in the lung and lymph nodes. The morbidity and mortality of guinea pigs at this stage is due to the combined effect of progressive pulmonary and extra-pulmonary pathology.

\section{Materials (also see Basic Protocol 3)}

Formalin (Fisher)

PBS

Petri dishes (6-7 per lung, with lids, disposable/non-sterile) (VWR)

Extra baggies

Paper towels

$5.0 \mathrm{ml}$ syringes fitted with $18-\mathrm{G}$ (guinea pig) or 26-G (mouse) needles (VWR)

Dissection instruments, sterile (medium dissection scissors, tissue forceps, small iris scissors, iris forceps, small toothed forceps, surgical scissors, dissecting pins)

$70 \%(\mathrm{v} / \mathrm{v})$ ethanol

$5 \%(\mathrm{v} / \mathrm{v})$ Lysol

$10 \%$ neutral-buffered formalin (VWR)

$15 \mathrm{ml}$ or $50 \mathrm{ml}$ polypropylene tube (Fisher)

Sterile polypropylene $250-500 \mathrm{ml}$ beaker (VWR)

Histology cassette (VWR)

\section{Preparing organs for pathological evaluation}

1. To obtain pathology samples from mice or guinea pigs during the infection the accessory mouse lung lobe or left pulmonary guinea pig lobe, portions of the spleen, lymph node and liver of each animal in each group are removed surgically (also see basic Protocol 3).

2. Each animal organ is then placed in a petri plates and infused in situ with $5 \mathrm{ml}$ of $10 \%$ neutral-buffered formalin (NBF) and placed in a histology cassette emerged in a $250 \mathrm{ml}$ flask containing $150 \mathrm{ml}$ of NBF or a $1 / 2$ full $15 \mathrm{ml}$ (mouse) or $1 / 2$ full $50 \mathrm{ml}$ (guinea pig) polypropylene tube overnight.

3. The NBF is then replaced (the following day) with fresh $10 \% \mathrm{NBF}(30 \mathrm{ml})$ and preserved until processing for histopathological assessment.

4. Organs are placed into $30 \mathrm{ml}$ of $10 \%$ NBF for fixation and left in the BSL-3 for 14 days prior to disinfection the container with $5 \%$ Lysol followed by $70 \%$ ethanol and removal from the BSL-3 area.

5. At the time of processing, all tissues are embedded in paraffin, sectioned at $5 \mu \mathrm{m}$, and stained with hematoxylin and eosin and acid fast bacilli staining for histologic evaluation and subsequent photography. We do not perform our histologic staining in our laboratory but prefer to contract this service by a qualified private company.

6. These should be reviewed by a veterinary pathologist; we recommend reviewing two serial sections from each guinea pig obtained from equivalent areas of the left cranial lung lobe. Our method of evaluation is to arrange sections from the least affected to the most severely affected based on lesion burden by sub-gross and 
microscopic examination. The sections can be further grouped into normal or mild lesions (Category 1), moderate severity lesions (Category 2) and severe lesions (Category 3). The overall ranking is then determined by ranking the number of sections that are classified as either mild moderate or severe in each group.

\section{BASIC PROTOCOL 5}

\section{MEASURING THE ANIMAL IMMUNE RESPONSE TO INFECTION}

Measuring the immune response in mice and guinea pigs to mycobacterial infections is now routine. Here we describe simple methods to detect responses by RT-PCR, by various Enzyme-Linked Immunosorbent Assay (ELISA)-based methods, and by flow cytometry.

Real time-PCR detection and quantification of cytokines in the mouse and guinea pig model-For these studies, we either use a mouse or guinea pig lung lobe, lymph node, spleen and/or liver (intravenous infection or aerosol infection) from each of five or four mice or guinea pig sacrificed at each time point of the experiment.

\section{Materials (also see Basic Protocol 3)}

Compatible instrument for iQ SYBR Green Supermix (iCycler iQ 5 - Bio- Rad)

Ice

iQ SYBR Green Supermix (Bio-Rad)

Template (cDNA or genomic DNA)

Forward and reverse primers

Pipettes and aerosol barrier pipette tips (MBP)

Sterile microcentrifuge tubes (Eppendorf)

Vortex mixer (VWR)

Optical qPCR microplates (Bio-Rad)

Nuclease free water (MBP)

Gloves (VWR)

RNase AWAY spray (MBP)

$q$ RT-PCR machine (iCycler iQ 5 Real-Time PCR Detection System, Bio-Rad)

\section{Sample collection}

1. Immediately following the sacrifice and as soon as possible after harvesting, the tissue should be placed directly in a tube containing $1 \mathrm{ml}$ of cold TRIzol reagent (Invitrogen).

2. At this point the tissue should be either; 1) homogenized, snap frozen in liquid Nitrogen and placed at $-80^{\circ} \mathrm{C}$, or 2) directly after collection, frozen in liquid Nitrogen and stored at $-80^{\circ} \mathrm{C}$ until will be homogenized after being shortly thawed, and then putting back in the $-80^{\circ} \mathrm{C}$ freezer.

NOTE: Normal precautions for handling RNA should be observed and RNase free glassware, filtered tips, tubes, RNase AWAY, should be used during all procedures. Before running a qRT-PCR reaction, is highly recommended to do a quality control (QC) of the samples to check their profile andRNA integrity with a 2100 expert Bioanalyzer 
(Agilent Technologies) or a similar system. All samples to be tested should be of the same concentration to be compared to each other.

\section{Quantitative real-time PCR protocol}

3. Thaw frozen SYBR Green super mixture, template and primers on ice.

4. Gently mix each tube to ensure thorough resuspension of components prior to use.

5. Briefly spin the tubes in a microcentrifuge to collect contents at the bottom of the tubes.

6. Prepare the SYBR Green (1X) from the (2X) that you will need for these reactions.

7. When all is ready, calculate and prepare the Cocktail to be used in each reaction, according to the number of samples that you have. Use the following table to calculate volumes. Always prepare $10 \%$ more reaction mix than required to compensate for potential pipeting loss.

\begin{tabular}{lcc}
\hline Reaction mix components: & for a $25 \mu 1$ total volume reaction per well. \\
SYBR Green (2X): & $12.5 \mu 1$ & $(1 \mathrm{X}$ concentration $)$ \\
Forward primer: & $0.5 \mu 1$ & $(9 \mu \mathrm{M})$ \\
Reverse primer: & $0.5 \mu 1$ & $(9 \mu \mathrm{M})$ \\
Ultra pure water: & $7.5 \mu 1$ & \\
Template: & $4.0 \mu 1$ & \\
\hline TOTAL: & $25.0 \mu 1$ & \\
\hline
\end{tabular}

NOTE: All samples should be run in duplicate. Each run should have at least one negative control (water), and one non- template control (NTC) per gene targeted, for which will detect possible contamination. Always run a reference gene (normalizer) such as $18 \mathrm{~S}$, HPRT or $\beta$ actin in the same plate of the targeted genes.

8. Turn the qRT-PCR machine ON in this order: system from DOWN to UP and then turn $\mathrm{ON}$ the computer. Let it warm-up for at least $10 \mathrm{~min}$ before you start the run.

9. Program the thermal cycler with the recommended real-time PCR protocol. For our primers we usually use the 2-step + Melt curve protocol (Denaturation and enzyme activation $95^{\circ} \mathrm{C} / 3: 00 \mathrm{~min} / 1 \times$, Denaturing $95^{\circ} \mathrm{C} / 0: 15 \mathrm{sec}$, Annealing and extension $60^{\circ} \mathrm{C} / 0: 20 \mathrm{sec} / 40 \times$, Melt Curve $95^{\circ} \mathrm{C} / 1: 00 \mathrm{~min} / 1 \times, 55^{\circ} \mathrm{C} / 1: 00 \mathrm{~min} / 1 \times$, $55^{\circ} \mathrm{C} / 10 \mathrm{sec} / 81 \times\left(\right.$ in $0.5^{\circ} \mathrm{C}$ increments $)$.

10. Select fluorophores.

11. Edit plate, using the Edit Plate Setup window, and identify samples, NTC and negative control in the plate.

12. Write the experiment's name and save it.

13. Load reaction replicates into PCR plates, and seal the reaction vessels. If necessary, store the sealed reactions on ice or at $4^{\circ} \mathrm{C}$ until you are ready to start running the Real-Time PCR protocol. 
14. Open the system, place the plate into it, close the door and RUN the plate.

15. When the run is done, a small window will appear on the screen. Save the data and now you can quit the program.

16. Close all windows, take the plate out from the system, log off, turn OFF the computer and then, turn OFF the system from UP to DOWN.

\section{Analysis of data}

17. For relative quantification the fold induction of mRNA is determined by comparing $C_{T}$ values of test samples verses $C_{T}$ values of control samples (reference gene values), by $\Delta \Delta C_{T}$ (Delta delta $C_{T}$ ) calculation method.

\section{Organ digestion and cell separation in the mouse and guinea pig Materials (also see Basic Protocol 3)}

Ice

Dissection instruments, sterile (medium dissection scissors, tissue forceps, small iris scissors, iris forceps, small toothed forceps, surgical scissors, dissecting pins)

$70 \%(\mathrm{v} / \mathrm{v})$ ethanol

$5 \%(\mathrm{v} / \mathrm{v})$ Lysol

BD $^{\mathrm{TM}}$ Liquid Counting Beads (BD PharMingen)

Mice

Dissection Board with pins

Sterile $15 \mathrm{ml}$ centrifuge tubes for lung collection (mouse)

Sterile $50 \mathrm{ml}$ centrifuge tubes for lung collection (guinea pig)

$50 \mathrm{ml}$ conical tube with EtOH

One 10-ml Syringe, filled with cold Heparin Solution [50 U/ml], per lung, fitted with 26 gauge needles (Sigma)

10 or 5 -ml syringe

Small Petri dishes

Sterile razor blades or long-sharp scissors (VWR)

Nylon cell strainer $(70 \mu \mathrm{m})(\mathrm{VWR})$

Collagenase/DNase solution (Incomplete dulbecco's modified Eagle's minimal essential medium (D-MEM) containing type IV bovine pancreatic DNAse (Sigma Chemical, $30 \mathrm{mg} / \mathrm{ml}$ ) and collagenase XI (Sigma Chemical, $0.7 \mathrm{mg} / \mathrm{ml}$ ))

Complete culture media (CMEM)

Incomplete media (DMEM) (Sigma)

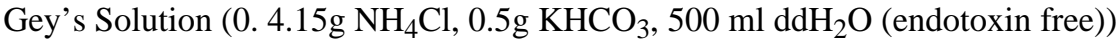

(Sigma)

Water bath at $37^{\circ} \mathrm{C}(\mathrm{VWR})$

Pipet boat 
1. Sacrifice mouse by $\mathrm{CO}_{2}$ asphyxiation. Place mouse on a paper towel and soak body with 70\% EtOH (also see basic Protocol 3).

2. In a BioSafety Cabinet Level II, place mouse on dissection board covered with a paper towel and pin "hands" and "feet" to dissection board so that mouse is vertically stretched out with its feet towards you.

3. Place surgical kit, in a 50-ml conical tube with $70 \% \mathrm{EtOH}$.

4. Make a $1 \mathrm{~cm} \mathrm{V-shaped} \mathrm{midline} \mathrm{incision} \mathrm{with} \mathrm{the} \mathrm{larger} \mathrm{dissection} \mathrm{scissors.}$

5. Retract the skin above the head and below the thighs by pulling it with gloved fingers vertically in opposite directions. Pin the upper portion of the skin over and above the head.

6. Grasp the Sternum with the forceps, and make a small V-shaped incision starting at the Xyphoid process of the sternum (don't cut deep or will cut the heart or lungs). Insert pointy scissor end into cut and slide laterally down both sides to open the thoracic cavity. Make a lateral cut towards the head at both sides of the ribs to further open the thoracic cavity. Lungs should be readily visible on either side of the heart. If you prefer, at this point you can open the abdomen and cut the descending aorta.

7. Hold the heart at the auricles level with the forceps. Using a 10-ml Syringe (mouse $25 \mathrm{ml}$ syringe (guinea pig) filled with ice-cold Heparin Solution insert the needle into the 'dark spot' on the right ventricle of the heart and inject the heparin until the lungs turn white and inflate.

8. Remove all lung lobes (mouse) or an individual lobe (guinea pig) and place in $2 \mathrm{ml}$ cold (mouse) or $4 \mathrm{ml}$ cold (guinea pig), incomplete media in $15 \mathrm{ml}$ (mouse) and 50 $\mathrm{ml}$ (guinea pig) tubes.

NOTE: It is recommended to weight all guinea pig tissues prior to placing them in tubes for cell number calculation base on 1 gram of tissue.

9. The lungs, as well as the draining lymph nodes and spleens are removed and placed in $2 \mathrm{ml}$ of cold, incomplete D-MEM.

NOTE: It is important to keep samples on ice at all times while processing to increase cellular viability.

10. Mouse carcasses should be double wrapped in autoclave bags.

11. Pour lungs from each sterile tube centrifuge tubes into separate small petri dishes.

12. Use sterile razor blades or scissors. It is recommended that you use EtOH to sterilize, rinse razor blades in incomplete-media before using on tissues. The organs are dissected into small pieces using razor blade or scissors. Carefully return the minced lung back into same tube.

NOTE: Place 5\% lysol each dish and place in biohazard bag and razors go into sharps container) (You can also use long-sharp scissors and mince the lungs directly in a conical tube prior to adding the digest solution.)

13. Add $2 \mathrm{ml}$ (mouse) or $4 \mathrm{ml}$ (guinea pig) of incomplete D-MEM containing type IV bovine pancreatic DNAse (Sigma Chemical, $30 \mathrm{mg} / \mathrm{ml}$ ) and collagenase XI (Sigma Chemical, $0.7 \mathrm{mg} / \mathrm{ml}$ ) is added for $30 \mathrm{~min}$ at $37^{\circ} \mathrm{C}$ on motion in the $\mathrm{H}_{2} \mathrm{O}$ bath.

NOTE: Use collagenase/ DNAse on all organs for routine analysis of macrophages and dendritic cells; however if not, then the lung is the only organ which needs collagenase/ DNAse treatment. 
14. Incubate is added for $30 \mathrm{~min}$ at $37^{\circ} \mathrm{C}$ on motion in the $\mathrm{H}_{2} \mathrm{O}$ bath.

15. To stop the digestion, add $10 \mathrm{ml}$ of incomplete D-MEM to the samples and placed on ice again.

16. To obtain cells from the lung, spleen and mediastinal lymph nodes the tissue should be pushed gently through cell screens with the plunger of a 10 or 5-ml syringe (rubber or plastic end). Some tissue will remain in strainer. Rinse strainer with $5 \mathrm{ml}$ media (mouse) and $10 \mathrm{ml}$ (guinea pig) media. Pipet cell solution back into the 15 $\mathrm{ml}$ tube (mouse) or $50 \mathrm{ml}$ (guinea pig).

17. For the guinea pig you will note that large amounts of fat will float on top of the cell suspensions; this can be removed by placing the cells in a small agar plate and tipping the plate to remove the cellular layer while the fat clings to the bottom of the agar plate and decant the cells off.

NOTE: The resultant single-cell suspension contains a variety of cells including both mononuclear and polymorphonuclear cells. The cell suspension should be kept on ice to avoid loss of any macrophages, which will stick to warm plastic.

18. Centrifuge 5 minutes at $1200 \mathrm{rpm}, 4^{\circ} \mathrm{C}$.

19. Pour off supernatant into pipet boat.

20. The remaining erythrocytes are lysed with $2 \mathrm{mls}$ (mouse) or $4 \mathrm{mls}$ (guinea pig) Gey's solution for 5 min at room temperature and then the cells are washed with Dulbecco's modified Eagle's minimal essential medium to neutralize Gey's Solution.

21. Centrifuge $5 \mathrm{~min} .1200 \mathrm{rpm}, 4^{\circ} \mathrm{C}$.

22. Decant supernatant and resuspend pellet by and add $1 \mathrm{ml}$ complete DMEM medium to each tube.

23. Place cell suspensions back on ice.

24. The remaining cells are then counted and plated at $1 \times 10^{6}$ per well in 96 -well plates. Total cell numbers are determined by flow cytometry using BD ${ }^{\mathrm{TM}}$ Liquid Counting Beads.

ELISA cytokine assay in the mouse-To determine the level of cytokines/chemokines produced by cell cultures of organs, macrophages or dendritic macrophages, or $\mathrm{T}$ cell overlays of antigen presenting cells, the supernantants are removed from the cell culture assays at different time points and can then be analyzed by ELISA or by cytometric bead array (CBA).

If you do not have a flow cytometer, simple ELISAs are the most straightforward method. Several companies produce matched antibody pairs and standards for many cytokines. Standard sandwich ELISA procedures are as follows:

\section{Materials (also see Basic Protocol 3 and 5 Basic Protocol)}

The majority of Standard sandwich ELISA Kits come with all the reagents and plates required for the assay. In addition, antibody pairs can be purchased from companies.

Immulon 2, 96 well flat bottom plates plates (Dynatech)

PBS: $0.85 \%$ (w/v) $\mathrm{NaCl}+0.1 \%$ Tween (PBST) 
$1 \%$ bovine serum albumin (Sigma)

Primary antibody in coating buffer

Biotinylated secondary antibody

Avidin-peroxidase

Standards

ELISA plate reader

\section{ELISA assay procedure}

1. Primary antibody at $1 \mu \mathrm{g} \mathrm{ml}^{-1}$ in coating buffer, $4^{\circ} \mathrm{C}$ overnight in Immulon 2 plates.

2. Flick out primary antibody and block the non-specific protein binding sites using $1 \%$ bovine serum albumin in PBST for two hours at room temperature.

3. Wash plate four times with PBST, add sample and standard diluted in cell culture medium. Leave at $4^{\circ} \mathrm{C}$ overnight.

NOTE: If samples are from infected animals this and the following steps should be performed under BSL3 conditions.

4. Wash plate four times with PBST. Add biotinylated secondary antibody at $1 \mu \mathrm{g}$ $\mathrm{ml}^{-1}$ in the BSA blocking solution and leave for $45 \mathrm{~min}$ at room temp.

5. Wash plate four times. Add avidin-peroxidase in working buffer and allow to develop.

6. Read plate on ELISA plate reader.

Cytometric bead array (CBA) cytokine assay in the mouse-A far superior assay is the cytometric bead array (CBA) (BD Biosciences) which has the advantage of reading 5 to 7 cytokines/chemokines at the same time from the same sample. The BD CBA system uses the sensitivity of amplified fluorescence detection by flow cytometry to measure soluble analytes in a particle-based immunoassay. Each bead in a BD CBA Kit provides a capture surface for a specific protein and is analogous to an individually coated well in an ELISA plate. The BD CBA capture bead mixture is in suspension to allow for the detection of multiple analytes in a small sample volume $(50 \mu \mathrm{l})$. These CBA kits allow for 100 sample analysis.

\section{Materials (also see Basic Protocol $\mathbf{3}$ and 5 Basic Protocol)}

All the CBA kits come with the majority of the reagents required for the assay.

Immulon 2, 96 well flat bottom plates (VWR)

Plastic $12 \times 75 \mathrm{~mm}$ sample acquisition tubes for a flow cytometer (eg, BD Falcon ${ }^{\mathrm{TM}}$

Cat. No. 352008)

PE detection reagent

Tin foil

Paper towels

Flow cytometer equipped with a $488 \mathrm{~nm}$ laser capable of detecting and distinguishing fluorescence emissions at 576 and $670 \mathrm{~nm}\left(\mathrm{eg}, \mathrm{BD}\right.$ FACScan ${ }^{\mathrm{TM}}$ BD FACSCalibur ${ }^{\mathrm{TM}}$ 
instruments) and BD CellQuest ${ }^{\mathrm{TM}}$ software is required. In addition you need to have BD CBA Software, or FCAP Array software (Cat. No. 641488).

\section{CBA assay procedure}

1. To perform, reconstitute mouse standards $(15 \mathrm{~min})$ in assay diluent and then dilute standards using the assay diluent.

2. You can use $5 \mathrm{ml}$ plastic sample acquisition tubes for a flow cytometer or reduce the volume required and use Immulon 2, 96 well plates. Then mix $10 \mu 1 /$ test of each mouse capture bead suspension.

NOTE: It is very important to vortex the tubes before aliquoting because the beads fall down to the bottom of the bottle quickly.

3. Then transfer $50 \mu 1$ of mixed beads to each assay tube and add standard dilutions and test samples to the appropriate sample tubes at $50 \mu \mathrm{l} / \mathrm{tube}$.

4. Also add PE detection reagent at $50 \mu 1 /$ test.

5. All of the samples and standards now need to be wrapped with tin foil to protect them from light and incubated at room temperature for 2 hours.

6. Then wash samples with $1 \mathrm{ml}$ wash buffer and centrifuge and then add $300 \mu \mathrm{l}$ of wash buffer to each assay tube and analyze samples on a flow cytometer.

\section{Analysis of cell surface expression of markers in the mouse by flow cytometry}

Materials (also see Basic Protocol 3 and 5 Basic Protocol)

PBS: $0.85 \%$ (w/v) $\mathrm{NaCl}+0.1 \%$ sodium azide (PBSA) (Sigma)

96-well round bottom plates (VWR)

Antibody with isotype control (BD Biosciences, eBioscience)

\section{Mouse cell surface assay procedure}

1. Re-suspended a single cell suspension at a concentration of $5 \times 10^{6}$ cells per $\mathrm{ml}$ in PBSA.

2. Cells are incubated in PBSA on ice for at least 30 minutes.

NOTE: This incubation is an important step if one is analyzing the expression of cell-surface activation molecules; this is because it is our experience that the antibody-mediated ligation of activation markers on the cell surface results in the up-regulation of several molecules that are used to determine cell activation status. For example, immediate incubation of cells with anti-CD44 and anti-CD45RB results in the cells becoming "blast cells" (as determined by an increase in scatter by flow cytometer analysis) and in the increased expression of CD44 on the cell surface.

3. Once cells have been incubated with PBSA, they are dispensed into 96-well plates ( $200 \mu \mathrm{l}$ per well) and centrifuged to pellet the cells.

4. The supernatant is removed by gently inverting the plate and discarding the contents into on to paper towels inside a Class II biosafety hood.

5. Antibody is added to the cells at appropriate concentrations, and the plate incubated for $30 \mathrm{~min}$ at $4^{\circ} \mathrm{C}$ in the dark. 
6. Following two washes in PBSA the cells are analyzed on a flow cytometer.

7. Recommended stains include:

Discriminating between cell populations: FITC anti-CD19 or CD45R/B220

(B cells), PE anti-CD3e (T ells), PerCP anti-CD4 (T-cell subset), APC anti-CD8 (T-cell subset); or FITC anti-NKl.1 (NK cell), PE anti-CD3e (T cell), PerCP antiCD4 (T-cell subset), APC anti-CD8 (T-cell subset).

Effector/ Memory T cell differentiation: FITC anti-CD44 (T-cell activation), PE anti-CD62L (T-cell memory), PerCP anti-CD3e (T cell), APC anti-CD4 or CD8 (Tcell subset); or FITC anti-CD44 (T-cell activation), PE anti-CD62L (T-cell memory), PerCP anti-CCR7 (T cell memory), APC anti-CD4 or CD8 (T-cell subset).

Regulatory T cell evaluation: FITC anti-CD25 (T-cell activation), PE anti-Foxp3 (Treg marker), PerCP anti-CD3e (T cell), APC anti-CD4 or CD8 (T-cell subset).

Macrophage/Dendritic cell evaluation: FITC anti-CD80 (cell activation), PE antiMHC class II (cell activation), PerCP anti-CD11b(macrophage/dendritic cell differentiation), APC anti-C11c (macrophage/dendritic cell differentiation).

NOTE: It is essential to include isotype controls for each individual antibody isotype that is used, in order to appreciate the contribution of non-specific binding.

Intracellular staining for cytokine production in the mouse-The capacity for a $\mathrm{T}$ cell to secrete certain cytokines can be measured using an intracellular cytokine staining protocol.

\section{Materials (also see Basic Protocol 3 and 5 Basic Protocol)}

PBS: $0.85 \%(w / v) ~ N a C l+0.1 \%$ sodium azide (PBSA)

96-well round bottom plates

Anti-CD3 and anti-CD28 antibody (BD Biosciences, eBioscience)

Monensin (BD Biosciences, eBioscience)

BDPharmingen, Fix/Perm reagent (BD Biosciences, eBioscience)

Antibody with isotype control (BD Biosciences, eBioscience)

Paper towels

Flow cytometer

\section{Mouse intracellular cytokine assay procedure}

1. Cells are harvested from the lungs and incubated with anti-CD3 and anti-CD28 (both at $0.2 \mu \mathrm{g} / 10^{6}$ cells), and monensin $(3 \mu \mathrm{M})$ for $4 \mathrm{~h}$ at $37^{\circ} \mathrm{C}, 5 \% \mathrm{CO}_{2}$.

2. Cells are harvested, washed in PBSA, and labeled with the outer cell surface markers as described in the analysis of cell surface expression of markers in the mouse by flow cytometry, and then fixed and permeabilized with a solution containing paraformaldehyde and saponin (BDPharmingen, Fix/Perm reagent).

3. Cells are then incubated with antibody specific for the cytokine of interest for 30 min at $4{ }^{\circ} \mathrm{C}$, in the dark. Cells are then washed twice and analyzed using a flow cytometer. 
NOTE: The use of isotype control antibody particularly for the cytokine reagent is essential in confirming that the (sometimes low) specific signal is real.

4. Recommended stains include:

Th1 cytokines produced by CD4 or CD8 T cells: FITC anti-IFN $\gamma$ PE anti-CD4, PerCP anti-CD8, APC anti-IL $\tilde{2}$

Th2 cytokine production by CD4 or CD8 T cells: FITC anti-IL-10 PE anti-CD4, PerCP anti-CD8, APC anti-IL- $\tilde{4}$

Th1 cytokines produced by Macrophages and Dendritic cells: FITC anti-IL-12 PE anti- TNF $\alpha$, PerCP anti-CD11b, APC anti-CD11 c

Th2 cytokines produced by Macrophages and Dendritic cells: FITC anti-IL-10 PE anti-TGF $\beta$, PerCP anti-CD11b, APC anti-CD11 ̃

Analysis of cell surface expression of markers in the guinea pig by flow cytometry-Flow cytometry in the guinea pigs to date has been difficult for various reasons, but we have recently been able to overcome most of the organ processing difficulties and gating problems, and can now use these new protocols to measure the major leukocytes that accumulate in infected lungs (Ordway 2007; Ordway 2008).

Regarding the previous difficulties with initial cell gating parameters, the traditional use of forward/side scatter (FSC/SSC) flow cytometric gating has proven difficult to adequately and consistently identify the distinct fractions of guinea pig leukocytes. We have now solved this by using gating based on SSC and a specific antibody [MIL4], which stains guinea pig granulocytes (heterophils/neutrophils, and eosinophils) (Ordway, 2007; Ordway, 2008). Gating out these cells allows a clean separation of the various subsets under analysis.

The primary drawback of the guinea pig model is the relative lack of specific immunological reagents with which to monitor the emerging acquired immune response in infected animals. This situation is gradually improving however with the availability of some antibodies to $\mathrm{T}$ cell markers (Serotec) and the development of PCR-based techniques to measure key cytokines and chemokines.

As yet, this model does not have the flexibility enjoyed by the mouse model. We are currently using CD45 and CT4 as "activation markers" on guinea pig CD4 and CD8 cells, but this still requires further validation. Regularly used markers such as CD44 and CD62L are not as yet available. A cross-reactive (anti-mouse) CD62 lectin domain antibody has been described, but we do not recommend this for the simple reason that CD62L does not exist in the guinea pig genome (this animal has E-selectin and P-selectin only), so what this antibody really stains (in low cell numbers) in the guinea pig is unknown.

\section{Materials (also see Basic Protocol $\mathbf{3}$ and 5 Basic Protocol)}

PBS: $0.85 \%$ (w/v) $\mathrm{NaCl}+0.1 \%$ sodium azide (PBSA)

96-well round bottom plates

Paper towels

Antibody with isotype control (Serotec)

Flow cytometer 


\section{Guinea pig cell surface assay procedure}

1. To analyze the expression of surface markers on cells derived from tissue, cells are prepared as described inte the Basic Protocol 5 and re-suspended at a concentration of $5 \times 10^{6}$ cells per $\mathrm{ml}$ in PBSA.

2. Cells are incubated in the PBSA on ice for at least 30 minutes.

3. After incubation with PBSA cells are dispensed into 96-well plates $(200 \mu 1$ per well) and centrifuged to pellet the cells.

4. The supernatant is removed by gently inverting the plate and and discarding the contents into on to paper towels inside a Class II biosafety hood.

5. Antibody is added to the cells at the appropriate concentration, and the plate incubated for $30 \mathrm{~min}$ at $4^{\circ} \mathrm{C}$, in the dark.

NOTE: As with the mouse, it is essential to include isotype controls for each individual antibody isotype that is used, in order to appreciate the contribution of non-specific binding.

6. Wash with PBSA two times.

7. Analyse the cells on a flow cytometer.

NOTE: It is recommended to incubate the secondary non-conjugated antibodies alone without adding conjugated antibodies to avoid nonspecific binding.

8. Recommended stains include:

Discriminating between T cell populations: FITC anti-CD4, FITC anti-CD8. APC anti-TCR.

Activated T cells: RPE anti- CD45 (T-cell activation), RPE anti-CT4 (homing receptor).

B cell evaluation: FITC anti-B cell, RPE anti-CD45 (activation marker).

Heterophils (neutrophils) /eosinophils: FITC anti-MIL4 (heterophils/eosinophils).

Macrophages: FITC anti-MR-1 (macrophage marker), RPE anti-MHC class II (cell activation).

Immunohistochemical analysis of cells in the lungs of mice and guinea pigsRelating flow cytometric data obtained from lung tissues to the actual location of these cells within the granuloma architecture is highly useful information and can be achieved by immunohistochemistry. We have described this technique for infected mouse lungs (Ordway 2006; Ordway 2007) and more recently for the guinea pig lung (Ordway 2007; Ordway 2008). Figure 4 shows a representative example of analysis of mouse and guinea pig lungs stained for CD4+ and CD8+ T cells.

\section{Materials (also see Basic Protocol 3 and 5 Basic Protocol)}

Acetone (Sigma)

Coplin jar (Sigma)

Peroxidase block (Biogenex)

3\% BSA-1X PBS (Sigma)

$\mathrm{H}_{2} \mathrm{O}$ from distilled $\mathrm{H}_{2} \mathrm{O}$ (Albertson) 
Goat serum reagent (Biogenex,)

Primary antibody and Isotype control (Serotec, BD Biosciences, eBioscience)

Secondary antibody: Goat $\mathrm{F}(\mathrm{ab})_{2}$ anti-rat Ig's conjugated to Horseradish peroxidase (HRPO) (Biosourse International)

Amionethylcarbazole (AEC) (Biogenex)

Meyer's Hematoxilyn (Biogenex)

Humidity chamber (Sigma)

Crystal Mounting Media (Biomeda)

OCT (Tissue-Tek)

Cryostat (Leica, CM, 1850)

\section{Sample collection}

1. For optimum results it is very important that specimens are collected and frozen as soon as possible in order to retain the morphology of the tissue and integrity of the antigens.

2. The lung tissue should be inflated with $30 \%$ OCT (in PBS) and placed in a tissue embedding cassette (Peel-Away, Polysciences, Inc., PA, USA). Care should be taken to ensure that at least $1 / 8$ of an inch of $100 \%$ OCT is above and below the specimen. The specimen should be central within the cassette. Once samples are placed correctly the cassette should be floated in liquid nitrogen until approximately two-thirds of the OCT turns white. Alternatively, the cassettes can be placed on dry-ice. Once frozen, cassettes can be wrapped in foil to avoid drying and can be stored at $-70^{\circ} \mathrm{C}$.

NOTE: Frozen blocks should be considered BSL3 agents as freezing may not kill the bacteria. Sections should be cut under BL3 conditions. We house our cryostat in a small room, separate from the rest of the BSL3 containment rooms. The operator should wear a protective mask and dispose of all debris as BSL3 material.

3. Cut serial sections of 7-10 microns thick in a cryostat, using tape transfer system.

4. Fix sections in cold acetone for 10 minutes in cryostat. Then air dry slides for 10-20 minutes at room temperature.

NOTE: After 10 minutes in acetone we do not see any viable $M$. tuberculosis bacilli.

\section{Immunohistochemical assay procedure}

5. Block endogeneous peroxidase with peroxidase block for 1 minute.

6. Wash slides in $3 \%$ BSA-1X PBS for five minutes.

7. Incubate sections at room temperature in a humidity chamber during 30 minutes with Goat serum reagent.

8. Drain slides and incubate overnight at $4^{\circ} \mathrm{C}$ in a humidity chamber with $500 \mathrm{ul} /$ slide of primary antibody or with the isotype control. 
9. Wash slides 3 times for $10-15$ minutes with $3 \%$ BSA-1X PBS. The last wash is completed with 1X PBS.

10. Drain slides and incubate for 40 minutes at $4^{\circ} \mathrm{C}$ in a humidity chamber with 500 $\mathrm{ul} / \mathrm{slide}$ of secondary antibody, Goat $\mathrm{F}(\mathrm{ab})_{2}$ anti-rat Ig's conjugated to Horseradish peroxidase (HRPO) (Biosourse International, Camarillo, CA). Suggested dilution of secondary antibody is 1:200.

11. Wash slides 3 times for $10-15$ minutes with $3 \%$ BSA-1X PBS. The last wash is completed with $1 \mathrm{X}$ PBS.

12. Develop the reaction using Amionethylcarbazole (AEC) as substrate (red color) for 10 minutes at room temperature.

13. Wash 1 time in distilled $\mathrm{H}_{2} 0,5-10$ minutes to stop the reaction.

14. Counterstain with Meyer's Hematoxilyn (color blue) for 30 seconds.

15. Wash 1 time in tap $\mathrm{H}_{2} 0,2-5$ minutes.

16. Dry slides for 1 minute, just remove nay excess of water

17. Add mounting media. Allow mounting media to dry up at room temperature overnight.

\section{SUPPORT PROTOCOL}

\section{CULTIVATION OF MYCOBACTERIA FOR USE IN ANIMAL EXPERIMENTS}

The proper cultivation of M. tuberculosis is an essential first step for any experiments utilizing animal modeling systems. Whether for aerogenic or intravenous inoculation, it is essential that the stock cultures be cultivated with standardized methods and media to assure that individual strains of $M$. tuberculosis have been cultivated under similar physiological conditions. Also, to compare data from experiments with different strains of M. tuberculosis, it is critical that the strains be grown in the same culture medium and under the same cultural conditions. This protocol outlines the basic cultivation of mycobacteria for use in animal modeling systems. Stock cultures are prepared as specific lots with documented titers and preparation conditions.

CAUTION: Mycobacterial specimens that are received for cultivation and ultimately used in animal models should be shipped to the laboratory in appropriate shipping containers in accordance with IATA interstate quarantine regulations (class 6.2 Category A, Infectious Substance affecting humans UN 2814. Most cultures are sent on dry ice which is a class 9 UN 1845 PI 904). The shipping container should contain appropriate documentation describing the mycobacterial strain and any data as to pathogenicity and/or drug resistance. All work with Mycobacterium tuberculosis must be done in an appropriate BSL-3 laboratory equipped with a Class II biosafety hood (see Strategic Planning).

There has been some discussion as to the merits of adding detergents to the culture medium as it may affect the pathogenicity or viability of the bacilli (Davis and Dubos, 1948; Dubos and Middlebrook, 1948; Dubos, 1950; Collins et al., 1974). We recognize this concern but feel that in order to achieve dispersed cultures free from large clumps, Tween is a necessary evil. For example, the necessity for smooth and evenly dispersed cultures is critical for the accurate delivery of bacilli for in vivo studies when the infection is given by aerosol. The aerosol device utilizes a glass venturi system to form tiny droplets containing the bacilli which are then delivered to a chamber containing the test animals over a specified period of time. If inocula from different isolates with different degrees of clumping were to be used, the data we would generate would be meaningless because of the wide variation in uptake, 
as well as the variation in particle size (i.e. size of rafts). On the other hand, with smooth evenly dispersed cultures the uptake parameters are highly reproducible. In fact we have demonstrated that aerosol infection results in an even distribution of bacilli in lungs using magnetic resonance imaging (MRI) (Kraft, 2004).

Another critical parameter is that all cultures used in biological experiments should be harvested at the same phase of growth. We like to harvest broth cultures when they are still in the log growth phase but before the culture enters into the late-log growth/stationary phase. At this point the culture is at its optimum concentration and viability. Cultures harvested at this time routinely have colony forming unit (cfu) counts at $5 \times 10^{7}$ up to a maximum of $10^{9}$ colonies per milliliter of broth. Higher concentrations are not recommended; when the culture gets in the range of $10^{9} \mathrm{cfu}$ per milliliter there is more clumping of the bacilli and many bacilli are probably dead. If necessary, the presence of non-viable bacilli in cultures can be detected by the presence of autolytic enzymes such as isocitrate dehydrogenase.

As described above, all manipulations with M. tuberculosis should be performed in a biological safety cabinet (Class II) within a biosafety level 3 facility. The establishment of a primary seed culture collection or repository is essential in maintaining the integrity of the individual clinical isolates as they are received. Proper documentation as to the source, date received, accession number, strain name, history of isolate, drug susceptibility, drug resistance and virulence data, should be maintained in a database. When a clinical isolate is received and unpacked it first needs to be evaluated as to whether there is sufficient growth for immediate subculture. In most instances clinical isolates of M. tuberculosis arrive in the research laboratory on Lowenstein-Jensen (LJ) slants (Jensen, 1932), but there are occasions when samples arrive in sealed serum vials containing broth cultures $(1.0-2.0 \mathrm{ml})$.

\section{Additional Materials (also see Basic Protocol 1)}

\section{M. tuberculosis cultures}

Proskauer Beck broth (PB), glycerol/alanine/salts (GAS) broth or 7H9 broth (Fisher)

Blood agar or trypticase soy or 7H11 or 7H10 agar plates (Fisher)

Plastic disposable inoculating loops (sterile)

Sterile $150 \times 25-\mathrm{mm}$ screw-cap culture tubes containing small magnetic stir bars (VWR)

10.0-ml sterile disposable serological pipets (VWR)

Mechanical pipetting device (e.g., Pipet-Aide)

250-ml polycarbonate Erlenmeyer culture flask (Corning 25600)

2.0-ml Wheaton serum vials with butyl rubber septa and aluminum crimp seals, all sterile (Wheaton Glass)

Avery labels (Avery)

24-well tissue culture dishes (VWR)

1-cc tuberculin syringes (VWR)

26-G needles (VWR)

Barrier type micropipet tips (VWR) 


\section{Establish mycobacterial broth cultures}

1. For a newly arrived shipment, carefully inspect the package containing the mycobacteria in a Class II biological safety cabinet. Open the package and examine for any leakage or damage within the shipping container.

CAUTION: If the culture has leaked, all absorbent material in the shipping container should be soaked with disinfectant (5\% Lysol or Amphyl) and then autoclaved. The original sender of the culture should be notified of the condition of the shipment.

2. Carefully remove the tubes containing the culture and place in a test tube rack in the biosafety cabinet.

Mycobacterial cultures from hospital, diagnostic, and research laboratories are usually shipped on Lowenstein-Jensen (LJ) slants. Cultures of M. tuberculosis are also shipped in freeze-dried vials, which should be reconstituted in 1 to $2 \mathrm{ml}$ of an appropriate broth (e.g., $\mathrm{PB}, \mathrm{GAS}$ or $7 \mathrm{H} 9$ broth).

3. Using a sterile plastic disposable inoculating loop, carefully remove a small amount of growth from an LJ slant culture and deposit into a sterile $150 \times 25-$ mm screw-cap culture tube containing $20 \mathrm{ml} \mathrm{PB}$ or GAS broth and a small magnetic stir bar. Alternatively, use a pipet to transfer the entire 1 to $2 \mathrm{ml}$ of reconstituted freeze-dried culture to $20 \mathrm{ml}$ broth. Carefully discard the inoculating loop or pipet into a pipet boat containing 5\% Lysol.

The use of disposable inoculating loops is recommended because metal loops pose an aerosol danger when flamed. Metal loops may be used if they are first stabbed into a small flask containing $70 \%$ ethanol with a bed of sand prior to being flamed in an electric loop incinerator.PB and GAS media are supplemented with $0.05 \%$ (v/v) Tween 80 to prevent clumping of the bacilli during growth.

4. Label the inoculated culture tubes with the following information: species ( $M$. tuberculosis), strain, medium, date, experimenter's name, drug resistance (yes/ no). Bag the pipet boat for autoclaving and disinfect the work surfaces of the biological safety cabinet.

The original cultures (LJ slants or reconstituted freeze-dried culture) can be stored for months at $4^{\circ} \mathrm{C}$ if further subcultures are needed. They should be autoclaved before discarding.

5. Place the new broth cultures into a plastic test tube rack secured to a magnetic stir plate in a $37^{\circ} \mathrm{C}$ incubator. Set the stir plate speed to low, allowing the small stir bars to gently agitate the broth.

6. Check the cultures for growth and possible contamination twice weekly.

After $\sim 2$ weeks the cultures should reach a density of $\sim 5.0 \times 10^{7}$ to 5.0 $\times 10^{8} \mathrm{cfu} / \mathrm{ml}$. At this density the cultures should be very hazy (e.g., printed text placed behind the tubes should be detectable but the letters should not be discernible). These cultures are in mid- to late-log-growth phase and can be subcultured into a larger volume of broth for production of a working stock for animal studies. 


\section{Subculture and produce working lots for animal experiments}

7. Carefully pipet the $20-\mathrm{ml}$ volume from each culture tube into a $250-\mathrm{ml}$ polycarbonate Erlenmeyer culture flask containing $150 \mathrm{ml}$ fresh PB, GAS or $7 \mathrm{H} 9$ broth, using a 10-ml sterile disposable serological pipet and a mechanical pipetting device.

8. Place the flasks in an incubator at $37^{\circ} \mathrm{C}$ and incubate for another 1 to 2 weeks.

The flasks can be placed on an orbital shaker (low speed with gentle agitation) or magnetic stir plate, or can be incubated stationary with occasional gentle swirling. After 1 to 2 weeks, the density should again be at $5.0 \times 10^{7}$ to $5.0 \times 10^{8} \mathrm{cfu} / \mathrm{ml}$.

9. Remove the flasks from the incubator and divide each culture into $1.5-\mathrm{ml}$ aliquots in sterile 2.0-ml Wheaton serum vials. Cap the vials with sterile butyl rubber septa and then seal by crimping with sterile aluminum seals.

The aliquots from a single 20-ml culture constitute one lot.

10. Disinfect vials by immersing in $70 \%$ ethanol and air dry. Label with small Avery labels printed with species, strain, date (lot), medium, and experimenter. Store at $-70^{\circ} \mathrm{C}$.

These vials are ready to be titered and used in animal studies.

\section{Determine titer of working lots}

11. Several days after freezing, thaw a random sample of vials (usually three or four per lot) at room temperature and vortex vigorously to break up any clumps of bacilli formed as a result of freezing.

Additionally, titers are periodically checked at time of use (see Basic Protocol 1, steps 8 to 12).

12. Pull back the aluminum seal from the top of the vial and disinfect the exposed butyl rubber septum with $70 \%$ ethanol.

13. Add $0.9 \mathrm{ml}$ sterile saline to the wells of a 24 -well tissue culture plate, using six wells (one row) for each vial being titered.

14. Use a 1-cc tuberculin syringe fitted with a $26-\mathrm{G}$ needle to remove $0.6 \mathrm{ml}$ of the first suspension. Apply $0.5 \mathrm{ml}$ to a blood agar, trypticase soy or $7 \mathrm{H} 11$ or $7 \mathrm{H} 10$ agar plate. Apply the remaining $0.1 \mathrm{ml}$ to the first well of one row in the 24-well dish and mix. Repeat for the remaining vials. Check these plates after a couple of days incubation.

Blood agar and trypticase soy agar plates are used to check the sterility of the culture (i.e., to check for other contaminants).

15. Using a micropipettor fitted with barrier-type pipet tips, transfer $100 \mu 1$ from the first well to the second, mix, and continue serially diluting each sample across its row of wells (final dilutions $1: 10$ to $1: 10^{6}$ ).

16. Remove $0.1 \mathrm{ml}$ from each dilution and plate onto $7 \mathrm{H} 10$ or $7 \mathrm{H} 11$ agar quadrant petri plates.

17. Bag the plates in resealable polypropylene sandwich bags (4 to 5 plates/bag) and incubate in the dark at $37^{\circ} \mathrm{C}$ for $\sim 3$ weeks. 
18. Count colonies on the $7 \mathrm{H} 10 / 7 \mathrm{H} 11$ agar plates and determine the titer $(\mathrm{cfu} / \mathrm{ml})$ of the original mycobacterial suspension in the vial using the following formula:

$$
\mathrm{cfu} / \mathrm{ml}=\frac{\mathrm{CC}_{\mathrm{Q}}}{V_{\mathrm{P}} \times \mathrm{DF}_{\mathrm{Q}}}
$$

where $\mathrm{CC}_{\mathrm{Q}}$ is the colony count in a given quadrant, $V_{\mathrm{P}}$ is the volume plated $(0.1$ $\mathrm{ml}$ ), and $\mathrm{DF}_{\mathrm{Q}}$ is the dilution factor in that quadrant.

19. Record the titer of each frozen lot into a culture collection log, notebook, or database.

\section{REAGENTS AND SOLUTIONS}

\section{Solid media}

7H10 and 7H11 agar quadrant petri plates-Both 7H10 and 7Hll agar media are routinely used for the cultivation and enumeration of $M$. tuberculosis by limiting dilution plating. The 7H11 agar contains a pancreatic digest in the base, whereas 7H10 does not; this additive seems to enhance the growth of many strains of mycobacteria and hence is the preferred medium in our laboratory. Both formulations, however, produce acceptable colony growth over a 3-week incubation at $37^{\circ} \mathrm{C}$.

\section{$21.0 \mathrm{~g} 7 \mathrm{H} 10$ or $7 \mathrm{H} 11$ agar base (Difco)}

$1.0 \mathrm{~g}$ asparagine (Sigma)

$5.0 \mathrm{ml}$ glycerol (Sigma)

$900 \mathrm{ml} \mathrm{H}_{2} \mathrm{O}$ (use deionized, distilled water in all recipes and protocol steps)

$100 \mathrm{ml}$ Middlebrook OADC enrichment medium (see recipe)

Prepare Middlebrook 7H10 or 7H11 agar: Dissolve 7H10 or 7H11 agar base, asparagine, and glycerol in $900 \mathrm{ml}$ water in a 2-liter Erlenmeyer flask capped with heavy aluminum foil. Autoclave at $121^{\circ} \mathrm{C}$ for $15 \mathrm{~min}$ at $15 \mathrm{psi}$ on slow exhaust. Remove the flask from the autoclave, place in a $57^{\circ} \mathrm{C}$ water bath, and allow the flask to stand for $45 \mathrm{~min}$. Remove the flask from the water bath, dry the bottom, and place in a wire basket for support in a laminar flow media cabinet. Carefully remove the aluminum foil top and aseptically add $100 \mathrm{ml}$ OADC enrichment medium while gently swirling the flask to mix. Prepare immediately before pouring quadrant petri plates.

After autoclaving, the agar should have an emerald green color. If it is brown or olive drab the agar should not be used. The 7H10 and 7H11 formulations contain malachite green, making the agar sensitive to light and extreme temperatures. If it has been overheated or the agar base has been exposed to light, the malachite green may have broken down into compounds that can inhibit the growth of mycobacteria.

Pour quadrant petri plates: In the laminar flow media cabinet, carefully unwrap a sterile 10$\mathrm{ml}$ dispensing syringe (Wheaton or Cornwall) and aseptically place the tubing from the syringe into the agar. An alternative protocol is to purchase an automatic plate dispensers are now available from many companies (Sigma, Fisher). Prime the syringe and dispense $5.0 \mathrm{ml}$ Middlebrook 7H10 or 7H11 agar per quadrant to X-petri plates (Falcon; $20 \mathrm{ml} /$ plate). Allow to solidify in the dark for $2 \mathrm{hr}$. Place plates in plastic storage containers and incubate in a dry incubator at $37^{\circ} \mathrm{C}$ for 24 to $48 \mathrm{hr}$ to check for contamination and allow the agar to cure. Place cured plates into resealable polypropylene bags ( 5 plates/bag) and label with type of agar, date, and lot. Store for up to 1 month at $4^{\circ} \mathrm{C}$. 
The curing step is essential to remove excess moisture from the agar. Uncured plates tend to weep or sweat upon long incubations and mycobacterial colonies will not form. Middlebrook 7H11 and 7H10 agar plates are available commercially, but usually in the standard $100-\mathrm{mm}$ petri dish format. The authors prefer quadrant plates, as they physically separate the serial dilutions plated onto the agar and thus prevent cross-contamination or mixing.

\section{Liquid media}

\section{GAS (glycerol/alanine/salts) broth}

Add to $990 \mathrm{ml} \mathrm{H}_{2} \mathrm{O}$ in the order listed, making sure each item is dissolved before adding the next:

0.3 g Bacto Casitone (pancreatic digest of casein; Difco)

$0.05 \mathrm{~g}$ ferric ammonium citrate (Sigma)

$4.0 \mathrm{~g} \mathrm{~K}_{2} \mathrm{HPO}_{4}$ (Sigma)

$2.0 \mathrm{~g}$ citric acid (anhydrous) (Sigma)

$1.0 \mathrm{~g}$ L-alanine (Sigma)

$1.2 \mathrm{~g} \mathrm{MgCl}_{2} \cdot 6 \mathrm{H}_{2} \mathrm{O}$ (Sigma)

$0.6 \mathrm{~g} \mathrm{~K}_{2} \mathrm{SO}_{4}$ (Sigma)

$2.0 \mathrm{~g} \mathrm{NH}_{4} \mathrm{Cl}$ (Sigma)

$10 \mathrm{ml}$ glycerol (Sigma)

Adjust to $\mathrm{pH} 6.6$ with $~ 1.8 \mathrm{ml} 40 \%$ (w/v) $\mathrm{NaOH}$

Add $0.5 \mathrm{ml}$ Tween 80 ( $0.05 \%$ final concentration)

Autoclave at $121^{\circ} \mathrm{C}$ for $15 \mathrm{~min}$ on slow exhaust

Store up to several months at $4^{\circ} \mathrm{C}$

Tween 80 can be added to prevent clumping of bacilli.

\section{Middlebrook OADC (oleic acid/albumin/dextrose complex) enrichment medium}

An alternative protocol is to purchase OADC (Dubos Media).

For albumin/dextrose/ $\mathrm{NaCl}$ solution, add to 3.8 liters $\mathrm{H}_{2} \mathrm{O}$ in the order listed:

$32.4 \mathrm{~g} \mathrm{NaCl}$ (Sigma)

$200 \mathrm{~g} \mathrm{BSA}$ (Fraction V) (Sigma)

$80 \mathrm{~g}$ dextrose (D-glucose) (Sigma)

Adjust pH to 7.0 with $40 \%$ (w/v) $\mathrm{NaOH}$

For sodium oleate solution:

$2.4 \mathrm{ml} 6 \mathrm{M} \mathrm{NaOH}$ (Sigma)

$2.4 \mathrm{ml}$ oleic acid (Sigma)

$120 \mathrm{ml} \mathrm{H}_{2} \mathrm{O}$

Warm in a $56^{\circ} \mathrm{C}$ water bath until the solution is clear 
For 4.0 liters $O A D C$ enrichment medium: Add $124.8 \mathrm{ml}$ sodium oleate solution to the albumin/dextrose $/ \mathrm{NaCl}$ solution and mix well. Sterile filter sequentially through $1.0 \mu \mathrm{m}$ and $0.2 \mu \mathrm{m}$ disposable cartridge filters (Gelman) using a peristaltic pump. Divide into aliquots in 100 -ml sterile bottles, cap, heat to $56^{\circ} \mathrm{C}$ for $1 \mathrm{hr}$, and then incubate overnight at $37^{\circ} \mathrm{C}$. Repeat the heating and incubation steps the following day. Inspect the bottles for contamination and store for up to 2 months at $4{ }^{\circ} \mathrm{C}$.

\section{Proskauer and Beck (PB) broth}

Add to 1 liter $\mathrm{H}_{2} \mathrm{O}$ in the order listed, making sure each item is dissolved before adding the next:

$5 \mathrm{~g} \mathrm{KH}_{2} \mathrm{PO}_{4}$ (Sigma)

$5 \mathrm{~g}$ Bacto Asparagine (Difco)

$0.6 \mathrm{~g} \mathrm{MgSO}_{4} \cdot 7 \mathrm{H}_{2} \mathrm{O}$ (Sigma)

$2.5 \mathrm{~g}$ magnesium citrate (Sigma)

$20 \mathrm{ml}$ glycerol (Sigma)

$0.5 \mathrm{ml}$ Tween 80 (0.05\% final concentration) (Sigma)

Adjust $\mathrm{pH}$ to 7.8 with 3 to $5 \mathrm{ml} 40 \%$ (w/v) $\mathrm{NaOH}$

Autoclave at $121^{\circ} \mathrm{C}$ for $15 \mathrm{~min}$ on slow exhaust (final $\mathrm{pH}$ 7.4)

Store up to several months at $4^{\circ} \mathrm{C}$

Tween 80 is added to prevent clumping of bacilli. If a precipitate forms after autoclaving, allow the medium to cool and remove the precipitate by filtration.

Autoclave again or sterile filter through a $0.2-\mu \mathrm{m}$ filter unit/cartridge (Gelman).

\section{Histology buffer}

\section{$10 \%$ neutral-buffered formalin (NBF)}

$40 \%$ (w/v) paraformaldehyde stock solution (Electron Microscopy Sciences)

PBS, sterile

To prepare formalin: Add $4 \%$ (w/v) Formalin to $10 \times$ PBS solution and mix and put in $10 \mathrm{ml}$ (mouse) or $25 \mathrm{ml}$ (guinea pig) syringes with needles for mouse or guinea pig organ perfusion.

Tissue needs to be completely submerged in $40 \%$ formalin for at least 48 hours before all bacteria are killed.

\section{Flow cytometry reagents}

\section{Incomplete DMEM media}

$500.0 \mathrm{ml}$ Dulbecco's Modification of Eagle's Medium (DMEM) (Sigma)

\section{Complete DMEM media}

$500.0 \mathrm{ml}$ Dulbecco's Modification of Eagle's Medium 1X DMEM (Sigma)

$50.0 \mathrm{ml}$ filter-sterilized Heat-Inactivated Fetal Bovine Serum (10\% FBS) (Sigma)

$5.0 \mathrm{ml}, 1 \mathrm{M}$ HEPES buffer (Sigma)

$5.0 \mathrm{ml}, 200 \mathrm{mM}$ L-Glutamine (Sigma) 
$5.0 \mathrm{ml},(100 \times)$ non-essential amino acids (Sigma)

$5.0 \mathrm{ml}, 100 \mathrm{mM}$ Sodium Pyruvate (Sigma)

$5.0 \mathrm{ml}$ antibiotic (optional) (100 ug/ml streptomycin; 100U/ml penicillin) (Sigma)

$500 \mu \mathrm{l} \beta$-Mercaptoethanol [50 uM stock] (optional)

\section{Heparin}

Heparin is an anticoagulant, which prevents blood from clotting during pulmonary inflation of lungs for use of these cells in flow cytometry.

200 g BSA(Fraction V1 vial Heparin Sodium Salt (Endotoxin Free) (Sigma)

Two $50 \mathrm{ml}$ conical tubes (VWR)

$100 \mathrm{ml}$ Phosphate Buffered Saline 1X (Sigma)

$10 \mathrm{ml}$ syringes (26 gage needles for lung digest)

Pipettman and pipettes (VWR)

Pipette boat (VWR)

Ice

To prepare heparin syringes: Inject approximately $2 \mathrm{ml} 1 \mathrm{X}$ PBS into the vial of heparin using a $3 \mathrm{ml}$ syringe and a 26-gauge needle (take $1 \mathrm{ml}$ from 2 separate $50 \mathrm{ml}$ tubes of $1 \mathrm{X}$ PBS), mix. Add $1 \mathrm{ml}$ back into each 49ml tube of $1 X$ PBS (150 units $/ \mathrm{ml}$ heparin). Fill up $10 \mathrm{ml}$ syringes with $10 \mathrm{ml}$ Heparin Solution place capped 26 gauge needles on ends after filled. Place syringes on at $4^{\circ} \mathrm{C}$.

\section{Geys solution}

Gey's solution is used for lysis of red blood cells in single cells suspension to be used for flow cytometry.
$4.15 \mathrm{~g} \mathrm{NH}_{4} \mathrm{Cl}$ (Sigma)
$0.5 \mathrm{~g} \mathrm{KHCO}_{3}$ (Sigma)

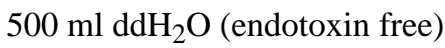

To prepare Geys solution: Weigh out compounds and add to $500 \mathrm{ml} \mathrm{ddH}_{2} \mathrm{O}$. Filter liquid through a $500 \mathrm{ml} 0.2 \mu$ filter unit and then store at $4^{\circ} \mathrm{C}$

\section{Collagenase/DNase solution}

Collagenase/DNase is used for organ tissue digestion.

$4.2 \mathrm{mg}$ Deoxyribonuclease I/DNase I, Type IV from bovine pancreas 150 units (Sigma)

1 bottle Collagenase Type XI (Sigma)

$15 \mathrm{ml}$ media (ICDMEM) (Sigma)

To prepare collagenase/dnase solution: Add the DNase and Collagenase to ICDMEM media and mix and filter sterilize through a $500 \mathrm{ml} 0.2 \mu$ filter unit or syringe. Aliquot $2 \mathrm{ml}$ of the solution to $15 \mathrm{ml}$ conical tubes and freeze at $-20^{\circ} \mathrm{C}$. This makes a 10X concentration. When ready to use, thaw and dilute to $10 \mathrm{ml}$ with ICDMEM media. This makes a $2 \mathrm{X}$ concentration that will be $1 \mathrm{X}$ when added to the tissue mixture to be digested. 


\section{COMMENTARY}

\section{Background Information}

Experimental mycobacterial infections are routinely performed in mouse and guinea pig models. The use of mice and guinea pigs for the study of M. tuberculosis infections has been well documented and has a lengthy historical background. Robert Koch utilized both animal models in his work, which led to the discovery of the tubercle bacillus and the formulation of his famous postulates (Koch, 1882, 1932). Guinea pigs were used in his initial studies of the tubercle bacillus and he was able to definitively demonstrate that inoculation of this animal with a pure culture of $M$. tuberculosis had the ability to produce tubercular disease. Koch subsequently continued this work with field mice and then with white mice, that were the offspring of pet mice belonging to his daughter Gertrude.

Since these initial investigations by Koch, other animal models such as the rabbit (Lurie, 1932; Lurie et al., 1952; Allison et al., 1962; Lurie and Dannenberg, 1965) and the rat (Lefford, 1984) have been also been developed for the study of mycobacterial infections. These animal models each have their merits, but to date the bulk of the experimental data has been obtained from the mouse and guinea pig systems.

The mouse model of mycobacterial disease is the most widely used both because of the huge number of immunological reagents available for this species, and because of its cost effectiveness. Mice require a relatively small area for housing as compared to guinea pigs or rabbits, and a large number of animals can be housed with standard caging and racks. The mouse is resistant to mycobacterial infection, attaining a strong immune response and giving rise to a chronic disease state when inoculated with strains of $M$. tuberculosis (Lefford, 1984). The growth of laboratory strains of $M$. tuberculosis following either aerogenic or intravenous inoculation is well defined with regard to the distribution of growth in primary target organs as well as subsequent dissemination into secondary organs (Collins, 1979; Collins and Montalbine, 1979; Orme, 1987).

One note of caution, however, is that the "laboratory" strains H37Rv and Erdman are of only moderate virulence in the murine model (Ordway, 2007) when compared to clinical isolates (particularly the newly emerging strains such as W-Beijing). Increasing evidence suggests that such clinical strains can induce distinctly different host immune responses, especially in terms of their ability to potently induce regulatory $\mathrm{T}$ cell and TH17 T cell populations (Ordway, 2007). This is worrisome as virtually all that we know to date, both in terms of testing new vaccines and new drugs, has been based almost exclusively on the use of the "laboratory" strains.

The mouse model is also well suited for immunological studies because of the availability of immunological reagents such as monoclonal antibodies to phenotypic cell surface markers and to cytokines (Orme, 1993, 1996; Orme et al., 1993). More recently, the availability of immunodeficient or gene-disrupted strains of mice has also significantly contributed to the study of the immune response to tuberculosis infection (Cooper et al., 1993, 1997; Florido et al., 1997). The testing of novel drug compounds (Kelly et al., 1996), immunotherapy, or vaccines (Orme, 1988, 1995; Roberts et al., 1995; Abou-Zeid et al., 1996; Huygen et al., 1996) in the treatment of tuberculosis can also be determined in the mouse model in an effective and economical manner. Virulence studies of the newly emerging multi-drug resistant strains of $M$. tuberculosis have been accomplished using aerogenic challenge, although extreme care must of course be undertaken due to biosafety considerations (Ordway et al., 1995; Ordway 2007). 
The guinea pig model is well suited to studies of mycobacterial infections due to the exquisite susceptibility of this animal to M. tuberculosis. It has been reported that guinea pigs can become infected with an aerogenic challenge with as few as 1 to 2 bacilli, producing an active infection (Smith et al., 1966; Smith and Harding, 1977). Guinea pigs are useful because they exhibit certain pathological aspects of tuberculosis disease that closely resemble disease seen in human patients. In addition, they give very strong delayed-type hypersensitivity (DTH) reactions, and hence are very useful in the development of new skin test reagents.

\section{Critical Parameters}

The infection of mice or guinea pigs via the aerogenic or intravenous route requires as a prerequisite the proper cultivation of stock mycobacterial cultures specifically for use in animal experimentation. It is essential that all mycobacterial stock cultures be cultivated under similar cultural and physiological conditions. The initial inocula, temperature, aeration, agitation, and subculture times for strains of mycobacteria need to be standardized. This standardization is important in performing animal infection studies with multiple isolates such as in virulence testing.

There are many methods available for the isolation and cultivation of mycobacteria and these are well outlined in numerous publications (Vestal, 1975; Youmans, 1979; Brown, 1983; Kubica and Wayne, 1984; Bloom, 1994). In general, the cultivation of mycobacteria has changed little over the years and many culture media have been utilized. For animal studies, the authors' laboratory routinely cultivates M. tuberculosis in either Proskauer and Beck broth or glycine/alanine/salts broth (see Reagents and Solutions) that has been supplemented with $0.05 \%$ Tween 80 detergent to prevent clumping of the bacilli during growth. Proskauer and Beck is a minimal salts/glycerol broth that has been modified from the medium initially developed by Youmans and Karlson (1947). It is best not to cultivate mycobacteria in media containing extraneous additives (such as $7 \mathrm{H} 9$ broth), because this type of medium requires the addition of oleic acid/albumin/dextrose complex (OADC). Mycobacteria in general, and especially M. tuberculosis, have a tendency in broth culture to clump or "raft" during growth. The incorporation of Tween 80 helps to eliminate this problem by allowing the bacilli to disperse and form a smooth even suspension.

It is extremely important when cultivating mycobacteria for animal studies that clumping be minimized or eliminated. Cultures grown in Tween-containing media can be assessed more accurately for the concentration of colony-forming units (cfu) via serial dilution plating on $7 \mathrm{H} 10$ or $7 \mathrm{H} 11$ agar or optical absorbance. Clumps or rafts of mycobacteria will not be delivered properly through the nebulizer unit of the IES and ultimately into the lungs of the test animals in an accurate and reproducible manner. Likewise, intravenous inoculation of clumpy mycobacterial suspensions will result in improper delivery of the inoculum and possible formation of emboli in the lungs. It is recommended that all mycobacteria cultivated for animal studies be grown in broth supplemented with Tween 80 .

The use of detergents such as Tween poses some special concerns as to the viability, pathogenicity, and growth of some strains of tuberculosis, and occasionally a problem culture may be encountered. Numerous investigators have debated the merits of using detergents to maintain smooth cultures while potentially altering the virulence of the isolate (Davis and Dubos, 1948; Dubos and Middlebrook, 1948; Dubos, 1950; Collins et al., 1974).

\section{Anticipated Results}

Mouse Aerosol Infections-Mice challenged aerogenically with common laboratory strains of M. tuberculosis (e.g., H37Rv or Erdman strains) at a dose of $\sim 10^{2}$ cfu develop an 
actively growing infection in the lungs that reaches a load of $\sim 10^{5} \mathrm{cfu}$ in the lungs between days 20 and 30. At day 20, dissemination of the bacilli can be detected in the spleen and liver $\left(\sim 10^{2} \mathrm{cfu}\right)$, which then increases to $\sim 10^{4} \mathrm{cfu}$ in the spleen at about day 40 .

The protective immune response begins to contain the infection by about day 20 . There may be some bacterial elimination, but by day 30 to 40 the infection assumes a chronic state in which the mycobacterial loads in the lungs $\left(\sim 10^{4} \mathrm{cfu}\right)$ and spleen $\left(\sim 10^{3} \mathrm{cfu}\right)$ tend to stabilize. This chronic state of infection is maintained for many months; however, the animal may eventually experience recrudescence or reactivation and active growth of the bacilli may resume.

The time to reactivation seems to differ within inbred strains of mice. Mice on the C57 background may not show evidence of reactivation until they reach median lifespan; other strains (such as CBA, AKR, or DBA/2) may reactivate only a few months after the infection is first contained. The basis for this is not known.

Mouse Intravenous Infections-Mice inoculated intravenously with $10^{5} \mathrm{cfu}$ of $M$. tuberculosis Erdman or H37Rv develop a systemic infection with a characteristic distribution of bacilli in various organs. Generally, the distribution follows a pattern in which $90 \%$ of the bacilli are taken up in the liver, $10 \%$ in the spleen, and $\sim 1 \%$ in the lungs (Collins and Montalbine, 1976; Orme, 1987). If necropsy and subsequent serial dilution analysis of these organs is performed immediately following inoculation and this pattern of distribution is not apparent, this usually indicates clumping of the mycobacterial stock culture used. Clumps or rafts of bacilli from a mycobacterial suspension that has not been cultivated properly for animal use will result in a shift in the distribution pattern, with a large percentage (often 50\%) of clumped bacilli being stuck in the pulmonary capillary circulation.

At approximately fifteen days after inoculation the infection reaches a load of $10^{7} \mathrm{cfu}$ in the spleen, $10^{6} \mathrm{cfu}$ in the liver, and $\sim 5 \times 10^{5} \mathrm{cfu}$ in the lungs. As protective immunity is established, a period of bacterial elimination ensues, followed by a chronic phase. In this latter phase the bacterial load is $\sim 10^{5} \mathrm{cfu}$ in the spleen, $10^{3} \mathrm{cfu}$ in the liver, and $\sim 5 \times 10^{5} \mathrm{cfu}$ in the lungs.

Guinea Pig Infections-Guinea pigs are very susceptible to infection with mycobacteria and an active infection can easily be established by uptake in the lungs of $\sim 10$ to $20 \mathrm{cfu}$ of M. tuberculosis. The bacterial load increases in the lungs rapidly over the first 20 to 30 days, reaching $\sim 10^{6}$ cfu by this time point. The infection then enters a chronic phase in which lung lesions develop central necrosis and begin to calcify, subsequently allowing reactivation and further growth of the bacilli. As a result, guinea pigs begin to lose weight and die of progressive pulmonary infection $\sim 15$ weeks post-exposure.

The disease that develops in the guinea pig following aerosol exposure to laboratory strains of M. tuberculosis H37Rv and Erdman is well documented and can be divided into acute, subacute and chronic stages of infection based on the pattern of bacterial growth and dissemination, as well as patterns of pulmonary and extra-pulmonary pathology (Ordway, 2007; Ordway 2008). Acute infection is characterized by an initial 3 day lag in bacterial growth, followed by a 14-20 day period of exponential bacterial growth in the lung and draining lymph nodes. This stage is also characterized by progression of granulomatous inflammation and necrosis in the primary granuloma of the lung and draining mediastinal lymph nodes. The immune response during this period of exponential bacterial growth is characterized by increasing numbers of activated CD4+ and CD8+ T cells, expression of MHC class II on macrophages and B cells migrating into the lungs and lymph nodes 
(Ordway, 2007; Ordway 2008). The subacute phase from 20 to 30 days is characterized by the emergence of a stationary phase of bacterial replication in the lung and lymph nodes. During this phase, the most severe inflammation within the primary lesion begins to subside and is replaced by a significant proportion of the normal tissue, particularly in the draining lymph nodes (Ordway, 2007; Ordway 2008). Importantly, in this subacute stage, infection is established in multiple extra-pulmonary sites such as the spleen and liver by hematogenous dissemination of bacilli. Concurrent with bacillemia and exponential bacterial growth in extra-pulmonary sites, there is re-infection of the lung by the hematogenous route.

Coincident with the establishment of a stationary phase of bacterial replication is the peaking of the acquire immune response which is characterized by the peaking of numbers of activated T cells, macrophages expressing MHC class II and B cells entering into the lungs and lymph nodes(Ordway, 2007; Ordway 2008). In addition, it is during this phase that granulocytes begin entering the lungs and lymph nodes in increasing numbers (Ordway, 2007; Ordway 2008). Finally, the chronic stage is characterized by continued bacterial replication in extra-pulmonary tissues but with a steady increase in bacterial numbers in the lung and lymph nodes. The waning of the acquired immune response during this phase is characterized by declining numbers of activated T cells, macrophages expressing MHC class II and increasing numbers of B cells and granulocytes entering into the lungs and lymph nodes (Ordway, 2007; Ordway 2008). The morbidity and mortality of guinea pigs at this stage is due to the combined effect of progressive pulmonary and extra-pulmonary pathology. These event can be rapid and particularly severe when clinical strains are tested; moreover, as with the mouse model, evidence for regulatory $\mathrm{T}$ cell induction has been noted (Palanisamy, 2008; Shang, 2010).

\section{Time Considerations}

Any experimental work with mycobacteria inherently takes time to perform due to the slow growth characteristics of this genus. The production of suitable stock cultures for use in animal experimentation can take from one to two months to complete. Initial cultivation in broth media and subcultivation takes about four weeks to accomplish. The growth of $M$. tuberculosis on solid media such as 7H10 or 7H11 agar can take about three weeks before visible colonies appear and can be enumerated for determination of cfu. Because of these restraints, the time course of animal experimentation with mycobacteria can take several months. Patience is a virtue!

\section{Acknowledgments}

We thank Laura Nold, Crystal Shanley, Megan Caraway, Marisa Harton, Dr. Andres Obregon, Dr. Marcela HenaoTamayo, Dr. Shaobin Shang, Dr. Susan Kraft and Dr. Randy Basaraba, and our colleagues in the Mycobacteria Research Laboratories for their contributions to the development of the methods described here. Several of the more modern approaches were developed using funding from NIH programs AI-40488, AI-44072, AI-41922, AI070456, AI081959, and a New Innovative Award (to D.O.). Additional funding leading to development of the guinea pig model was generously provided by the Bill \& Melinda Gates Foundation.

\section{Literature Cited}

Abou-Zeid C, Gares MP, Inwald J, Janssen R, Zhang Y, Young DB, Hetzel C, Lamb JR, Baldwin SL, Orme IM, Yeremeev V, Nikonenko BV, Apt AS. Induction of a type 1 immune response to a recombinant antigen from Mycobacterium tuberculosis expressed in Mycobacterium vaccae. Infect. Immun. 1996; 65:1856-1862. [PubMed: 9125572]

Allison MJ, Zappasodi P, Lurie MB. Host-parasite relationships in natively resistant and susceptible rabbits on quantitative inhalation of tubercle bacilli. Am. Rev. Respir. Dis. 1962; 85:553-569. [PubMed: 13860623]

Basaraba RJ. Experimental tuberculosis: the role of comparative pathology in the discovery of improved tuberculosis treatment strategies. Tuberculosis. 2008; 88:S35-S47. [PubMed: 18762152] 
Basaraba RJ, Bielefeldt-Ohmann H, Eschelbach EK, Reisenhauer C, Tolnay AE, Taraba LC, Shanley CA, Smith EA, Bedwell CL, Chlipala EA, Orme IM. Increased expression of host iron-binding proteins precedes iron accumulation and calcification of primary lung lesions in experimental tuberculosis in the guinea pig. Tuberculosis. 2008; 88:69-79. [PubMed: 17942369]

Bloom, BR., editor. Tuberculosis-Pathogenesis Protection, and Control. Washington, D.C.: American Society for Microbiology; 1994.

Brown, IN. Animal models and immune mechanisms in mycobacterial infection. In: Ratledge, C.; Stanford, J., editors. Biology of Mycobacteria. Vol. Vol. 2. London: Academic Press; 1983. p. 173-234.

CDC (Centers for Disease Control). Core Curriculum on Tuberculosis. 3rd ed.. Atlanta: CDC; 1994.

CDC (Centers for Disease Control). Proposed Guidelines for Goals for Working Safely with Mycobacterium tuberculosis in Clinical, Public Health and Research Laboratories. Atlanta: CDC; 1998.

CDC/NIH (Centers for Disease Control/National Institutes of Health). Biosafety in Microbiological and Biomedical Laboratories. Bethesda, Md: CDC, Atlanta, and NIH; 1993. HHS Publication No. 93-8395 (CDC)

CDC/NIOSH (Centers for Disease Control/National Institute of Occupational Safety and Health). National Institutes of Occupational Health, Respiratory Protective Devices: Final Rules and Notice. Federal Register 42 CFR Part 84. 1995; 60:30335-30398.

Collins FM. Cellular antimicrobial immunity. Crit. Rev. Microbiol. 1979; 7:27-91.

Collins FM, Montalbine V. Distribution of mycobacteria grown in vivo in the organs of intravenously infected mice. Am. Rev. Respir. Dis. 1976; 113:281-286. [PubMed: 816236]

Collins FM, Wayne LG, Montalbine V. The effect of cultural conditions on the distribution of Mycobacterium tuberculosis in the spleens and lungs of specific pathogen-free mice. Am. Rev. Respir. Dis. 1974; 110:147-156. [PubMed: 4278310]

Cooper AM, Dalton DK, Stewart TA, Griffin JP, Russell DG, Orme IM. Disseminated tuberculosis in interferon gamma gene-disrupted mice. J. Exp. Med. 1993; 178:2243-2247. [PubMed: 8245795]

Cooper AM, D'Souza C, Frank AA, Orme IM. The course of Mycobacterium tuberculosis infection in the lungs of mice lacking expression of either perforin- or granzyme-mediated cytolytic mechanisms. Infect. Immun. 1997; 65:1317-1320. [PubMed: 9119468]

Davis BD, Dubos RJ. The inhibitory effect of lipase on the bacterial growth in media containing fatty acid esters. J. Bacteriol. 1948; 55:11-23.

Dubos RJ. The effect of organic acids on mammalian tubercle bacilli. J. Exp. Med. 1950; 92:319-332. [PubMed: 14778913]

Dubos RJ, Middlebrook G. The effect of wetting agents on the growth of tubercle bacilli. J. Exp. Med. 1948; 83:409-423.

Florido M, Appelberg R, Orme IM, Cooper AM. Evidence for a reduced chemokine response in the lungs of beige mice infected with Mycobacterium avium. Immunology. 1997; 90:600-606. [PubMed: 9176115]

Huygen K, Content J, Denis O, Montgomery DL, Yawman AM, Deck RR, DeWitt CM, Orme IM, Baldwin S, D’Souza C, Drowart A, Lozes E, Vandenbussche P, Van Vooren JP, Liu MA, Ulmer JB. Immunogenicity and protective efficacy of a tuberculosis DNA vaccine. Nat. Med. 1996; 2:893-898. [see comments]. [Comment in Nat. Med. 1996, 2:857-859.]. [PubMed: 8705859]

Kelly BP, Furney SK, Jessen MJ, Orme IM. Low-dose aerosol infection model for testing drugs for efficacy against Mycobacterium tuberculosis. Antimicrob. Agents Chemother. 1996; 40:28092812. [PubMed: 9124846]

Koch R. Aetiologie der Tuberculose. Berlin Klin. Wochenscher. 1882; 19:221-230.

Koch R. Die Aetiologie der Tuberculose. Am. Rev. Tuberc. 1932; 25:285-323.

Kraft SL, Dailey D, Kovach M, Stasiak KL, Bennett J, McFarland CT, McMurray DN, Izzo AA, Orme IM, Basaraba RJ. Magnetic resonance imaging of pulmonary lesions in guinea pigs infected with Mycobacterium tuberculosis. Infect. Immun. 2004; 72:5963-5971. [PubMed: 15385500]

Kubica, GP.; Wayne, LG., editors. Microbiology Series. Vol. Vols. 15A/B. New York: Marcel Dekker; 1984. The Mycobacteria: A Sourcebook. 
Lefford, MJ. Diseases in mice and rats. In: Kubica, GP.; Wayne, LG., editors. The Mycobacteria: A Sourcebook. Microbiology Series. Vol. Vol. 15. New York: Marcel Dekker; 1984.

Lenaerts AJ, Degroote MA, Orme IM. Preclinical testing of new drugs for tuberculosis: current challenges. Trends Microbiol. 2008; 16:48-54. [PubMed: 18182291]

Lurie MB. The correlation between the histological changes and the fate of living tubercle bacilli in the organs of tuberculous rabbits. J. Exp. Med. 1932; 55:31-54. [PubMed: 19869977]

Lurie MB, Dannenberg AM. Macrophage function in infectious disease with inbred rabbits. Bacteriol. Rev. 1965; 29:466-476. [PubMed: 16350185]

Lurie MB, Abramson S, Heppleston AG. On the response of genetically resistant and susceptible rabbits to the quantitative inhalation of human-type tubercle bacilli and the nature of resistance to tuberculosis. J. Exp. Med. 1952; 95:119-134. [PubMed: 14907965]

Middlebrook GM. An apparatus for airborne infection of mice. Proc. Soc. Exp. Biol. Med. 1952; 80:105-110. [PubMed: 14930088]

McMurray DN. Hematogenous reseeding of the lung in low-dose, aerosol-infected guinea pigs: unique features of the host-pathogen interface in secondary tubercles. Tuberculosis. 2003; 83:131-134. [PubMed: 12758202]

McMurray DN, Allen SS, Jeevan A, Lasco T, Cho H, Skwor T, Yamamoto T, McFarland C, Yoshimura T. Vaccine-induced cytokine responses in a guinea pig model of pulmonary tuberculosis. Tuberculosis. 2005; 85:295-301. [PubMed: 16253558]

Ordway D, Henao-Tamayo M, Harton M, Palanisamy G, Troudt J, Shanley C, Basaraba RJ, Orme IM. The hypervirulent Mycobacterium tuberculosis strain HN878 induces a potent TH1 response followed by rapid down-regulation. J. Immunol. 2007; 179:522-531. [PubMed: 17579073]

Ordway D, Palanisamy G, Henao-Tamayo M, Smith E, Shanley C, Orme IM, Basaraba RJ. Cellular immune responses during Mycobacterium tuberculosis infection in the guinea pig. J. Immunol. 2007; 179:2532-2541. [PubMed: 17675515]

Ordway DJ, Sonnenberg MG, Donahue SA, Belisle JT, Orme IM. Drug-resistant strains of Mycobacterium tuberculosis exhibit a range of virulence for mice. Infect. Immun. 1995; 63:741743. [PubMed: 7822053]

Ordway D, Henao-Tamayo M, Shanley C, Smith EE, Palanisamy G, Wang B, Basaraba RJ, Orme IM. The influence of BCG vaccination on the cellular immune response in immune guinea pigs infected with Mycobacterium tuberculosis. Cellul. Vaccine Immunol. 2008; 15:1248-1258.

Ordway D, Higgins DM, Sanchez-Campillo J, Spencer J, Henao-Tamayo M, Harton M, Orme I, Gonzalez-Juarrero M. XCL1 (lymphotactin) chemokine produced by activated CD8 T cells during the chronic stage of infection with Mycobacterium tuberculosis negatively affectsproduction of IFN- $\gamma$ by CD4 T cells and participates in granuloma stability. J Leukocyte Biol. 2007; 82:12211229. [PubMed: 17699612]

Ordway D, Shanley C, Caraway M, Orme E, Bucy D, Hascall-Dove L, Henao-Tamayo M, Harton M, Shang S, Ackart D, Kraft S, Lenaerts A, Basaraba R, Orme I. Evaluation of standard chemotherapy in the guinea pig model of tuberculosis. Antimicrob Agents Chemother. 2010; 54:1820-1833. 2010. [PubMed: 20160055]

Orme IM. The kinetics of emergence and loss of mediator T lymphocytes acquired in response to infection with Mycobacterium tuberculosis. J. Immunol. 1987; 138:293-298. [PubMed: 3097148]

Orme IM. Induction of nonspecific acquired resistance and delayed-type hypersensitivity, but not specific acquired resistance in mice inoculated with killed mycobacterial vaccines. Infect. Immun. 1988; 56:3310-3312. [PubMed: 3141288]

Orme IM. Immunity to mycobacteria. Curr. Opin. Immunol. 1993; 5:497-502. [PubMed: 8216924]

Orme IM. Prospects for new vaccines against tuberculosis. Trends Microbiol. 1995; 3:401-404. [PubMed: 8564360]

Orme IM. Immune responses in animal models. Curr. Top. Microbiol. Immunol. 1996; 215:181-196. [PubMed: 8791714]

Orme IM, Andersen P, Boom WH. T cell response to Mycobacterium tuberculosis. J. Infect. Dis. 1993; 167:1481-1497. [PubMed: 8501346]

Orme IM. Mouse and guinea pig models for testing new tuberculosis vaccines. Tuberculosis. 2005; 85:13-17. [PubMed: 15687022] 
Orme IM. Safety issues regarding new vaccines for tuberculosis, with an emphasis on post exposure vaccination. Tuberculosis. 2006; 86:68-73. [PubMed: 16260181]

OSHA (Occupational Safety and Health Administration). Occupational Exposure to Bloodborne Pathogens, Final Rule. Washington, D.C.: Department of Labor, OSHA; 1991. (document 29 CFR, part 1910.1030)

Palanisamy GS, Smith EE, Shanley CA, Ordway D, Orme IM, Basaraba RJ. Disseminated disease severity as a measure of virulence of Mycobacterium tuberculosis in the guinea pig model. Tuberculosis. 2008; 88:295-306. [PubMed: 18321783]

Rhoades ER, Frank AA, Orme IM. Progression of chronic pulmonary tuberculosis in mice aerogenically infected with virulent Mycobacterium tuberculosis. Tuber. Lung Dis. 1997; 78:5766. [PubMed: 9666963]

Roberts AD, Sonnenberg MG, Ordway DJ, Furney SK, Brennan PJ, Belisle JT, Orme IM. Characteristics of protective immunity engendered by vaccination of mice with purified culture filtrate protein antigens of Mycobacterium tuberculosis. Immunology. 1995; 85:502-508. [PubMed: 7558141]

Shaobin S, Harton M, Henao Tamayo M, Shanley C, Palanisamy GS, Caraway M, Chan ED, Basaraba $\mathrm{RB}$, Orme IM, Ordway DJ. Increased induction of Foxp3+ regulatory T cells in guinea pigs infected with W-Beijing strains of Mycobacterium tuberculosis. JID. 2010 In press.

Smith DW, Harding GE. Animal model: Experimental airborne tuberculosis in the guinea pig. Am. J. Pathol. 1977; 89:273-276. [PubMed: 910875]

Smith DW, Wiegeshaus EH, Navalkar R, Grover AA. Host-parasite relationships in experimental airborne tuberculosis. I. Preliminary studies in BCG-vaccinated and nonvaccinated animals. J. Bacteriol. 1966; 91:718-724. [PubMed: 4956758]

Vestal, AL. Procedures for the Isolation and Identification of Mycobacteria. Atlanta: Center for Disease Control; 1975.

Williams A, Hall Y, Orme IM. Evaluation of new vaccines for tuberculosis in the guinea pig model. Tuberculosis. 2009; 89:389-397. [PubMed: 19815462]

Youmans, GP. Tuberculosis. Philadelphia: W.B. Saunders; 1979.

Youmans GP, Karlson AG. Streptomycin sensitivity of tubercle bacilli: Studies on recently isolated tubercle bacilli and the development of resistance to streptomycin in vivo. Am. Rev. Tuberc. 1947; 55:529. [PubMed: 20253121] 


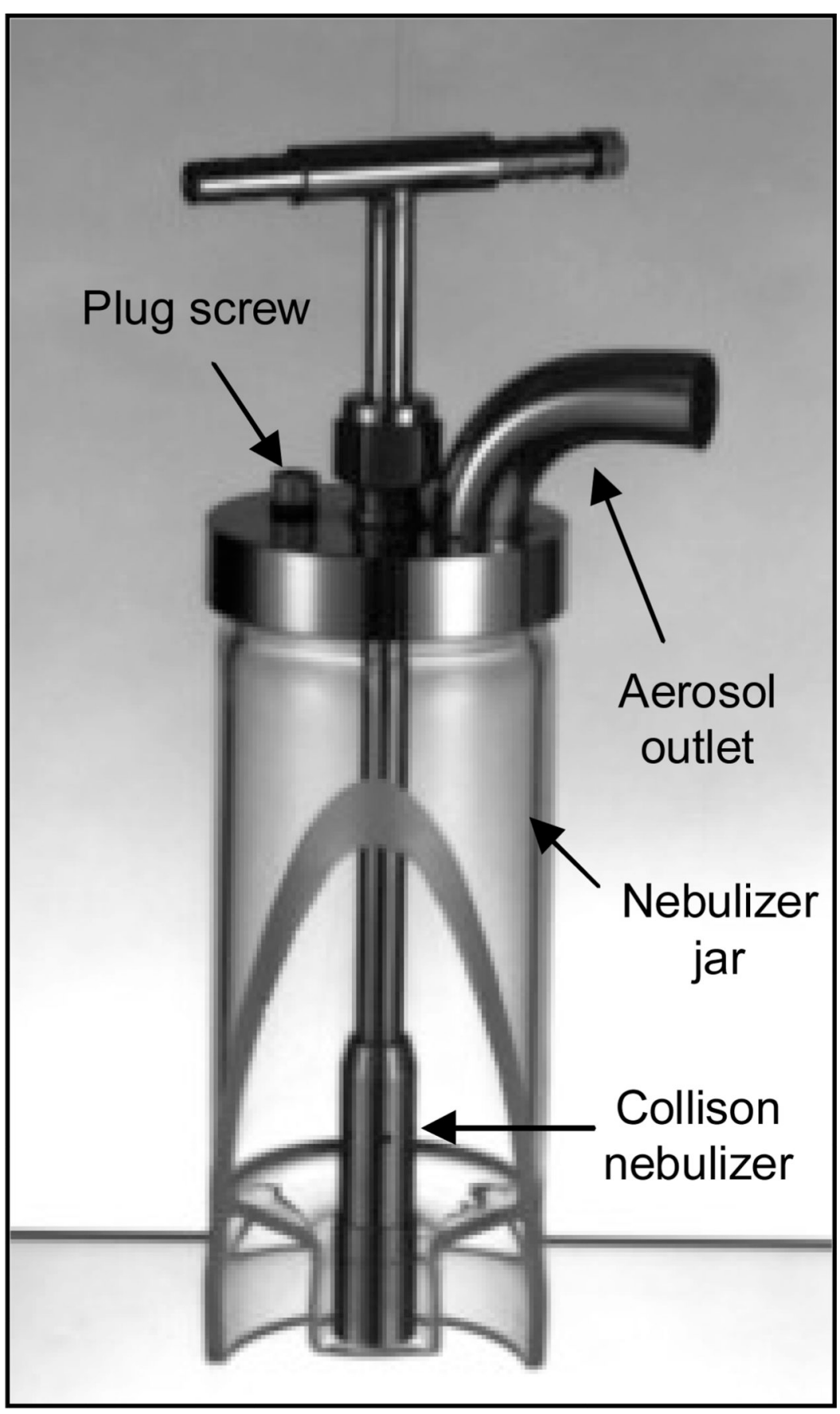

Figure 1.

Diagram of the Collison nebulizer unit, complete with the surrounding glass nebulizer jar. 

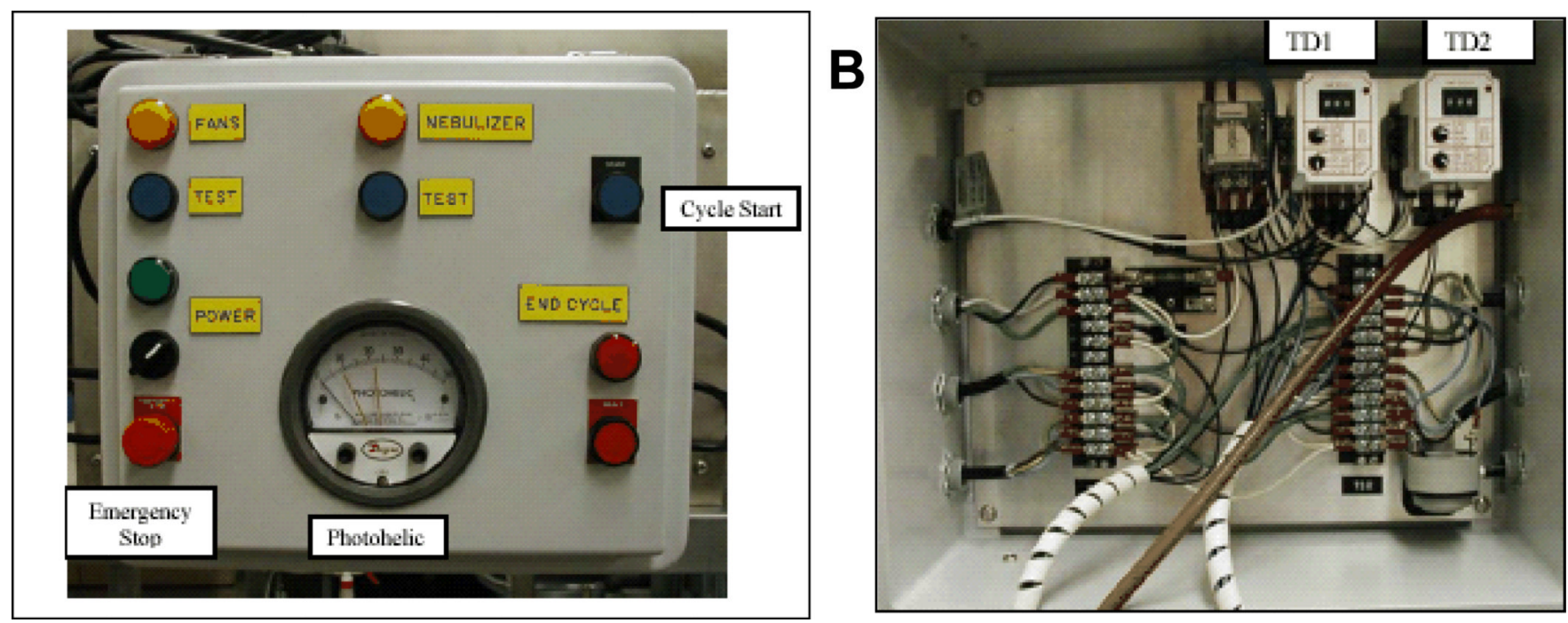

Figure 2.

The exterior (Panel A) and interior (Panel B) of the Madison chamber Control Box. 


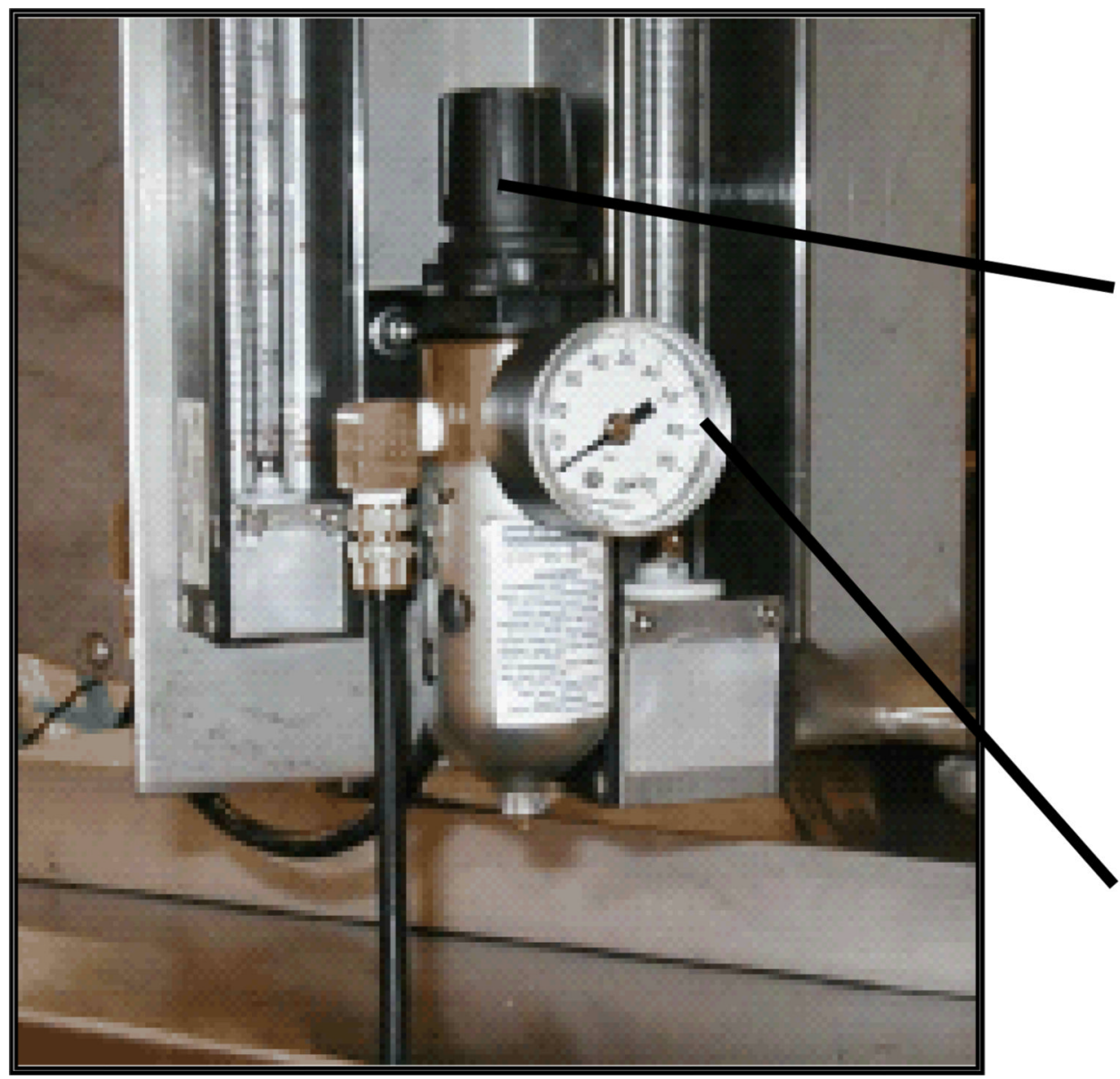

\section{Regulator dial}

Pressure gauge

Figure 3.

Diagram of the flow panel. The flow meter on the right indicates the secondary airflow, or air being pumped through the system by the vacuum/compressor unit. The flow meter on the left indicates the primary airflow (the air being channeled through the nebulizer unit determined by the pressure regulator (at center). 


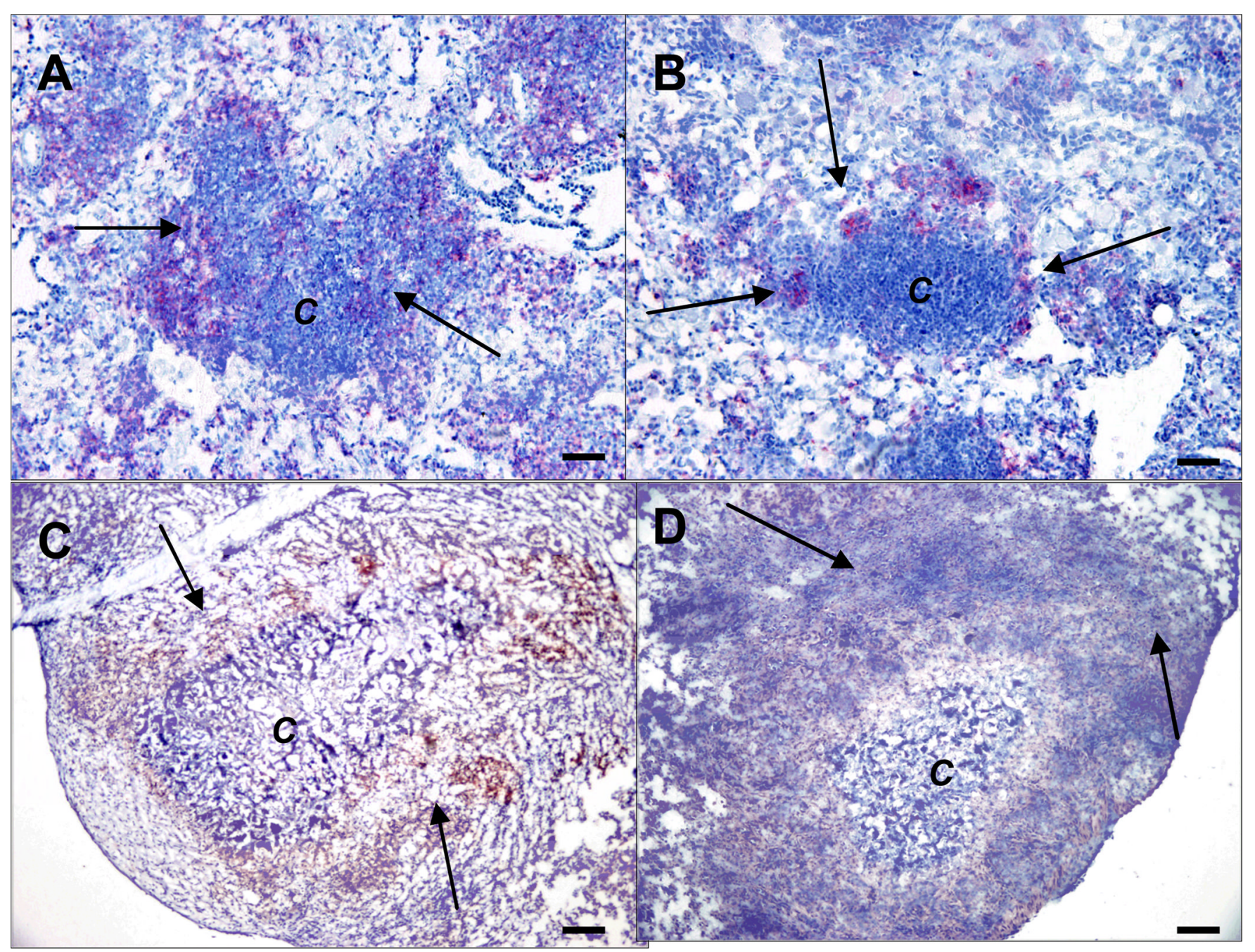

Figure 4.

Immunohistochemical staining of CD4 and CD8 T cells in mouse and guinea pig lungs during the course of $M$. tuberculosis infection. Representative mouse photomicrographs from granuloma lung sections with the center of the granuloma (c) from mice show red immunohistochemical staining for CD4+ (A) and CD8+ (B) T cells. Representative guinea pig photomicrographs from granuloma lung sections with the central necrosis $(c)$ show red immunohistochemical staining for $\mathrm{CD} 4+(\mathrm{C})$ and $\mathrm{CD} 8+(\mathrm{D})$ after 30 days of the infection, illustrating co-localization of staining. Bars indicate, total magnification $\mathrm{A}, \mathrm{B}=10 \times$ and $\mathrm{C}$, $\mathrm{D}=4 \times$.

This Figure shows a representative example of immunohistochemical analysis of mouse and guinea pig lungs stained for $\mathrm{CD} 4+$ and $\mathrm{CD} 8+\mathrm{T}$ cells. 